This item was submitted to Loughborough's Research Repository by the author.

Items in Figshare are protected by copyright, with all rights reserved, unless otherwise indicated.

\title{
Multi-physics investigations on the dynamics of differential hypoid gears
}

PLEASE CITE THE PUBLISHED VERSION

http://dx.doi.org/10.1115/1.4027403

PUBLISHER

() ASME

VERSION

AM (Accepted Manuscript)

LICENCE

CC BY-NC-ND 4.0

REPOSITORY RECORD

Mohammadpour, Mahdi, Stephanos Theodossiades, and Homer Rahnejat. 2019. "Multi-physics Investigations on the Dynamics of Differential Hypoid Gears". figshare. https://hdl.handle.net/2134/14291. 


\title{
Multi-physics investigations on the dynamics of differential hypoid gears
}

\author{
M. Mohammadpour ${ }^{\#}$, S. Theodossiades ${ }^{1 \#}$ and H. Rahnejat
}

\author{
"Wolfson School of Mechanical \& Manufacturing Engineering, \\ Loughborough University, Loughborough, UK
}

\author{
${ }^{1}$ Corresponding Author: S.Theodossiades@lboro.ac.uk \\ Tel: + 44 (0) 1509227664 Fax: + 44 (0) 1509227648
}

\begin{abstract}
Vehicular differential hypoid gears play an important role on the Noise, Vibration and Harshness (NVH) signature of the drive train system. Additionally, the generated friction between their mating teeth flanks under varying load-speed conditions is a source of power loss in a drive train, whilst absorbing some of the vibration energy. The paper deals with the coupling between system dynamics and analytical tribology in a multi-physics, multi-scale analysis. Elastohydrodynamic lubrication of elliptical point contact of partially conforming hypoid gear teeth pairs with nonNewtonian thermal shear of a thin lubricant film is considered, including boundary friction as the result of asperity interactions on the contiguous surfaces. Tooth Contact Analysis (TCA) has been used to obtain the input data required for such an analysis. The dynamic behaviour and frictional losses of a differential hypoid gear pair under realistic operating conditions are therefore determined. The detailed analysis shows a strong link between NVH refinement and transmission efficiency, a finding not hitherto reported in literature.
\end{abstract}




\section{Keywords}

Hypoid gear pair dynamics, Multi-physics multi-scale analysis, Drive train NVH, Mixed elastohydrodynamics

\section{Nomenclature:}

$\mathrm{A}_{\mathrm{a}}$ - Asperity contact area

$A_{f}$ - Vehicle frontal area

$a$ - Vehicle acceleration

$b$ - Half amount of backlash

$C_{D}$ - Drag coefficient of vehicle

$c^{\prime}$ - Solid thermal capacity

$c_{m}$ - Structural meshing damping

$c_{p x}$ - Pinion bearing damping in $\mathrm{x}$ direction

$c_{p y}$ - Pinion bearing damping in y direction

$c_{p z}$ - Pinion bearing damping in $z$ direction

$c_{g x}$ - Gear bearing damping in $\mathrm{x}$ direction

$c_{g y}$ - Gear bearing damping in y direction

$c_{g z}$ - Gear bearing damping in z direction

$E^{\prime}$ - Reduced elastic modulus of the contact:

$2 /\left(\left(1-\vartheta_{p}^{2}\right) /_{E_{p}}+\left(1-\vartheta_{g}^{2}\right) / E_{g}\right)$

$E_{r}$ - Reduced elastic modulus of the contact:

$\pi E^{\prime} / 2$

$E_{p}$ - Young's modulus of elasticity of the

pinion

$E_{g}$ - Young's modulus of elasticity of the gear $e(t)$ - Static unloaded transmission error

$F_{t r}$ - Transmitted force

$F_{a}$ - Axial load on bearing

$F_{r}$ - Radial load on bearing

$F_{f l}$ - Normal load of flank

$F_{t}$ - Total meshing load

$f_{r}$ - Total flank friction

$f_{r l}$ - Is the rolling resistance coefficient

$f_{b}$ - Boundary friction contribution

$f_{v}$ - Viscous friction contribution

$h_{c 0}$ - Dimensionless central film thickness

$I_{p}$ - Moment of inertia of the pinion

$I_{g}$ - Moment of inertia of the gear

$\dot{K}$ - Lubricant conductivity

$K^{\prime}$ - Surface solid conductivity

$K_{n}$ - "Inner ring - Element - Outer ring"

nonlinear stiffness

$k_{m}(t)$ - Meshing stiffness

$k_{p x}$ - Pinion bearing stiffness in $\mathrm{x}$ direction

$k_{p y}$ - Pinion bearing stiffness in y direction

$k_{p z}$ - Pinion bearing stiffness in z direction 
$k_{g x}$ - Gear bearing stiffness in $\mathrm{x}$ direction

$k_{g y}$ - Gear bearing stiffness in y direction

$k_{g z}$ - Gear bearing stiffness in z direction

$M$ - Vehicle mass

$m$ - Equivalent mass in the direction of the

line of action

$m_{p}$ - Mass of the pinion

$m_{g}$ - Mass of the gear

$\bar{p}$ - Average pressure

$R_{p}(t), R_{g}(t)$ - Pinion and gear contact radii

$R_{a}$ - Aerodynamic resistance

$R_{r l}$ - Rolling resistance

$R_{G}$ - Gravitational resistance

$R_{t}$ - Transmission ratio

$R^{\prime}$ - Equivalent radius of contact

$T_{a p}, T_{a g}$ - Applied torque to the pinion and

gear

$T_{p}, T_{g}$ - Externally applied torque to the

pinion and gear

$T_{f r p}, T_{f r g}$ - Frictional moments at pinion and

gear

$\mathrm{U}^{\prime}$ - Speed of entraining motion

$U_{g}$ - The component of gear motion along the

instantaneous line of action

$U_{p}$ - The component of pinion motion along

the instantaneous line of action
V - Vehicle speed

W- Vehicle weight

$\mathrm{W}_{\mathrm{a}}$ - Load carried by asperities

$\mathrm{x}_{\mathrm{p}}$ - Pinion lateral displacement in $\mathrm{x}$ direction

$x_{g}$ - Gear lateral displacement in $\mathrm{x}$ direction

$y_{p}$ - Pinion lateral displacement in y direction

$y_{g}$ - Gear lateral displacement in y direction

$z_{p}$ - Pinion lateral displacement in z direction

$z_{g}$ - Gear lateral displacement in z direction

\section{Greek symbols:}

$\alpha$-Pressure viscosity coefficient

$\beta$ - Average asperity tip radius

$\gamma$-Slope of the lubricant limiting shear stress-

pressure dependence

$\eta_{0}$ - Lubricant dynamic viscosity at

atmospheric pressure

$\theta$ - Angle of entraining motion

$\vartheta_{p}$ - Poisson's ratio of the pinion material

$\vartheta_{\mathrm{g}}$ - Poisson's ratio of the gear material

$\lambda$ - Stribeck's oil film parameter

$\lambda_{\text {cr- }}$ Critical film ratio

$\mu$ - Coefficient of friction

$v$ - Poisson's ratio

$\xi$ - Asperity density per unit area

$\rho$ - Air density

$\rho^{\prime}$ - Solid surface density 


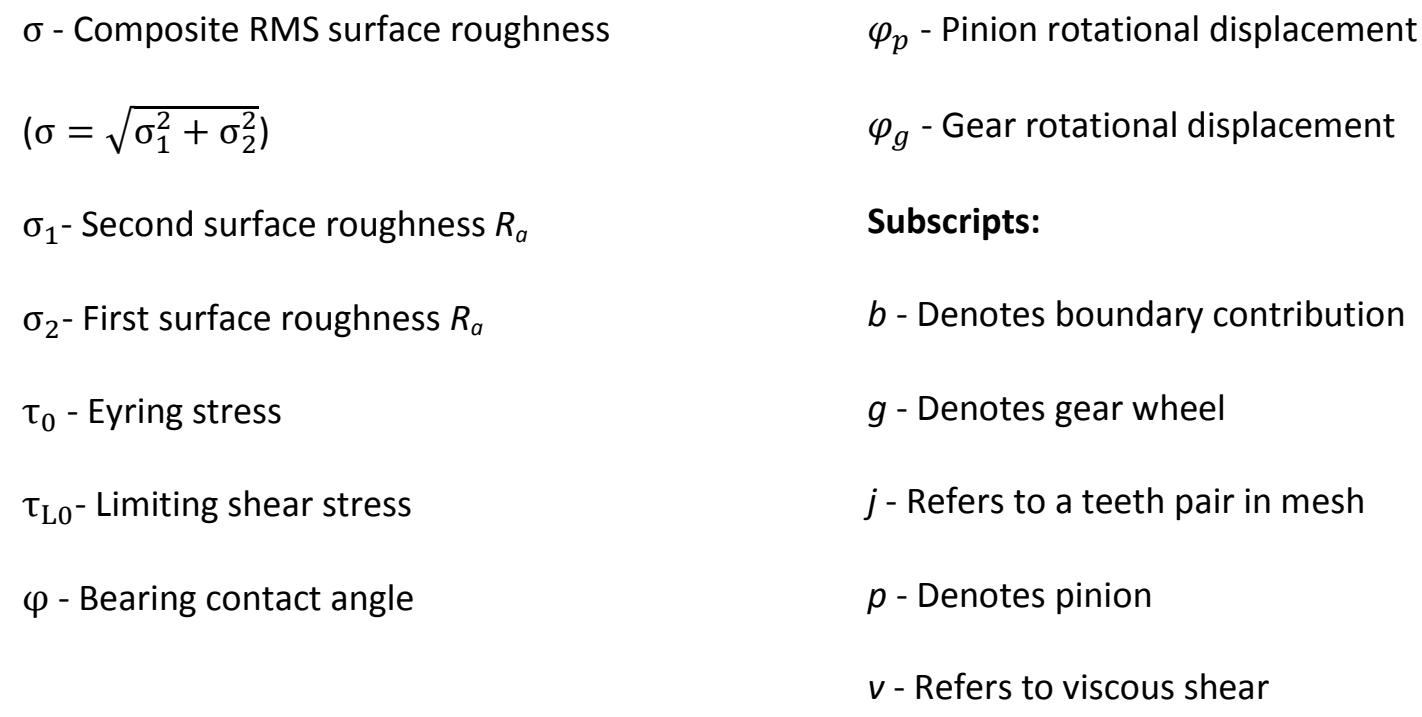

\section{Introduction}

Vehicle differential hypoid gears are usually subjected to varying load-speed conditions. Key concerns are transmission efficiency, refinement of Noise, Vibration and Harshness (NVH), and mitigating wear/fatigue. Multi-physics models are essential tools when investigating such multi-purpose integrated studies, because there are strong interactions between gear dynamics and contact tribology. This is mainly through generated conjunctional friction between the meshing teeth pairs. Friction is regarded as a major source of power loss in an otherwise lightly damped power train system. It consumes some of the excess engine order vibration energy, which is the underlying cause of various drive train NVH phenomena, such as transmission rattle [1] and axle whine [2]. Thus, friction consumes some energy and improves upon the lightly damped nature of the powertrain.

Dynamics of gear pairs have been extensively studied, particularly for parallel axis transmissions [3-5]. There are fewer investigations of non-parallel axis gears, such as hypoid and bevel gears. This is because of the complexity of contact kinematics and meshing characteristics. The dynamic model of rear axle gears was studied by Remmers [6] in order to predict resonant conditions. Some experiments were also conducted to confirm the coincidence of vibration peaks with the generated noise. A two degree-of- 
freedom vibration model of a pair of bevel gears was investigated by Kiyono et al [7] for stability analysis, where the line-of-action vector was modelled using a sinusoidal form.

Abe et al [8] carried out experiments to show that that axle gear noise could be reduced by modifying the prevailing vibration mode with the addition of an inertial disk. This can be mounted onto either side of the final drive flanges. Another experimental method was proposed by Hirasaka et al [9] to study the body and driveline sensitivity to the transmission error of an axle hypoid gear pair. It was found that the dynamic mesh force was affected by the torsional vibration characteristics of the driveline system. A dynamic model of a hypoid gear set was developed by Donley et al [10], where the mesh point and line-of-action were considered as time invariant. More recently, hypoid gear kinematic models, based on the exact teeth geometry have been proposed [11-13] in order to study the gear pair dynamics with transmission error excitation and Non-Linear Time Variant (NLTV) mesh characteristics. In another work, an NLTV dynamic model of a hypoid gear pair with mesh parameters, represented by a sinusoidal form, was used to investigate the system response [14]. A multi-point mesh model was developed by Wang [15], which was used to analyse the hypoid gear dynamics. In all the above investigations, the time-dependent teeth mesh parameters were expressed in the form of either fundamental harmonics or by inclusion of a few harmonic orders.

A dynamic model including time varying contact parameters was developed by Wang et al [16]. The model took into account the backlash non-linearity. Results showed a number of interesting non-linear characteristics, such as the jump phenomenon, as well as sub-harmonic and chaotic behaviours. These characteristics were reported for lubricated contacts earlier in $[17,18]$, who also showed the lightly damped nature of lubricated contacts under high load, where the lubricant merely acts as an amorphous incompressible solid. A multi-body model of a TORSEN differential, considering component flexibility was presented by Virlez et al [19], comprising rigid and flexible bodies, constrained by flexible gear pair joints. The four working modes of the differential were observed with good accuracy. A new formulation for the calculation of transmission error was presented in [20], which took into account the derivative of the static 
transmission error, where a parametric study of a hypoid gear pair with time variant mesh characteristics was presented.

The mechanical inefficiencies in gearing, arising from the lubricated meshing gear pairs, where a line contact footprint approximation is made with flow along the contact width was investigated [21-22]. Other researchers have used the more realistic assumption of elliptical point contact footprint in hypoid gear teeth pair meshing [23-25]. However, the input torque was relatively low, not representative of vehicle differential conditions. Also, the lubricant inlet entrainment flow vector was assumed to be along the minor axis of the contact ellipse. However, experimental evidence [26] and numerical investigations [27-29] have suggested significant side-leakage flow from the contact footprint along the major axis of the contact ellipse. The repercussions of ignoring the side leakage flow is breach of continuity of flow condition, as well as errors introduced in the evaluation of contact temperatures due to the side leakage flow out of the contact. The assumption of a line contact footprint can be considered as reasonable under conditions that promote an elliptical point contact of large aspect ratio [30]. In Kahraman et al [21, 22], Elastohydrodynamic Lubrication (EHL) was assumed for the gear meshing problems. Tooth Contact Analysis (TCA) was used for the completeness of the solution and elliptical contact conditions were assumed at relatively low contact loads. Recently, Mohammadpour et al [31] also used TCA in the EHL calculations of a hypoid gear pair with angled inlet flow and point contact assumptions. However, the reported work did not take into account the dynamics of the gear pair. In De la Cruz et al [32], a tribo-dynamic investigation was conducted for helical gears, taking into account the torsional oscillations of the gear wheels.

In this paper, a multi-physics model of differential hypoid gears is presented, incorporating the lateral/axial and torsional oscillations of the gear supporting shafts. Due to the geometric complexity of the interacting teeth surfaces, TCA is used to obtain the required gear input data (CALYX software was employed). These include the time-dependent varying geometry of contact and teeth meshing stiffness. The non-linear characteristics of the support bearings are also considered. System dynamics and analytical approach to contact tribology are coupled (tribo-dynamics). Due to the high transmitted loads, EHL elliptical point contact is assumed with non-Newtonian lubricant shear of thin films, as well as thermal effects and 
interaction of real rough surfaces. The above features constitute a novel multi-physics analysis framework, which can be used to extract information about various important aspects of the differential's operation (motion of the gear wheels, dynamic transmission error and friction) in a transient manner. This is a more comprehensive approach compared with the conventional numerical tools, which put emphasis on either the system dynamics or lubricated conjunctions along the contacting teeth flanks. The parametric study reveals potential design rules to control the characteristics of the transmitted force to the differential casing, affecting the NVH signature of the vehicle.

\section{Methodology}

\section{1- Multi-Body model}

\section{Equations of motion:}

The mechanical system of the hypoid gear pair (Fig. 1) comprises eight degrees of freedom (lateral/axial and torsional motions of the shafts). Shaft bending slope effects have not been considered due to evidence in the literature relating to their rather insignificant effects on the system dynamics. This has been demonstrated experimentally (Fujii et al. [33]) and numerically (Yinong et al. [34], Yang and Lim [35]) for similar systems. This assumption is also made considering the centred position of the gear wheel between symmetric bearings according to figure 1-a (similar to the configuration of cylindrical gears) and also relatively stiff carrier shaft of the gear, which make the bending slope even less. The point of origin $O$ (also used in the TCA) is defined by the intersection of the pinion normal plane (containing the pinion axis) and the gear axis The corresponding multi-body dynamics model has been developed in the commercial software ADAMS (Fig. 1), using constrained Lagrangian dynamics. The inertial properties of the mating gear pair are listed in Table 1. 

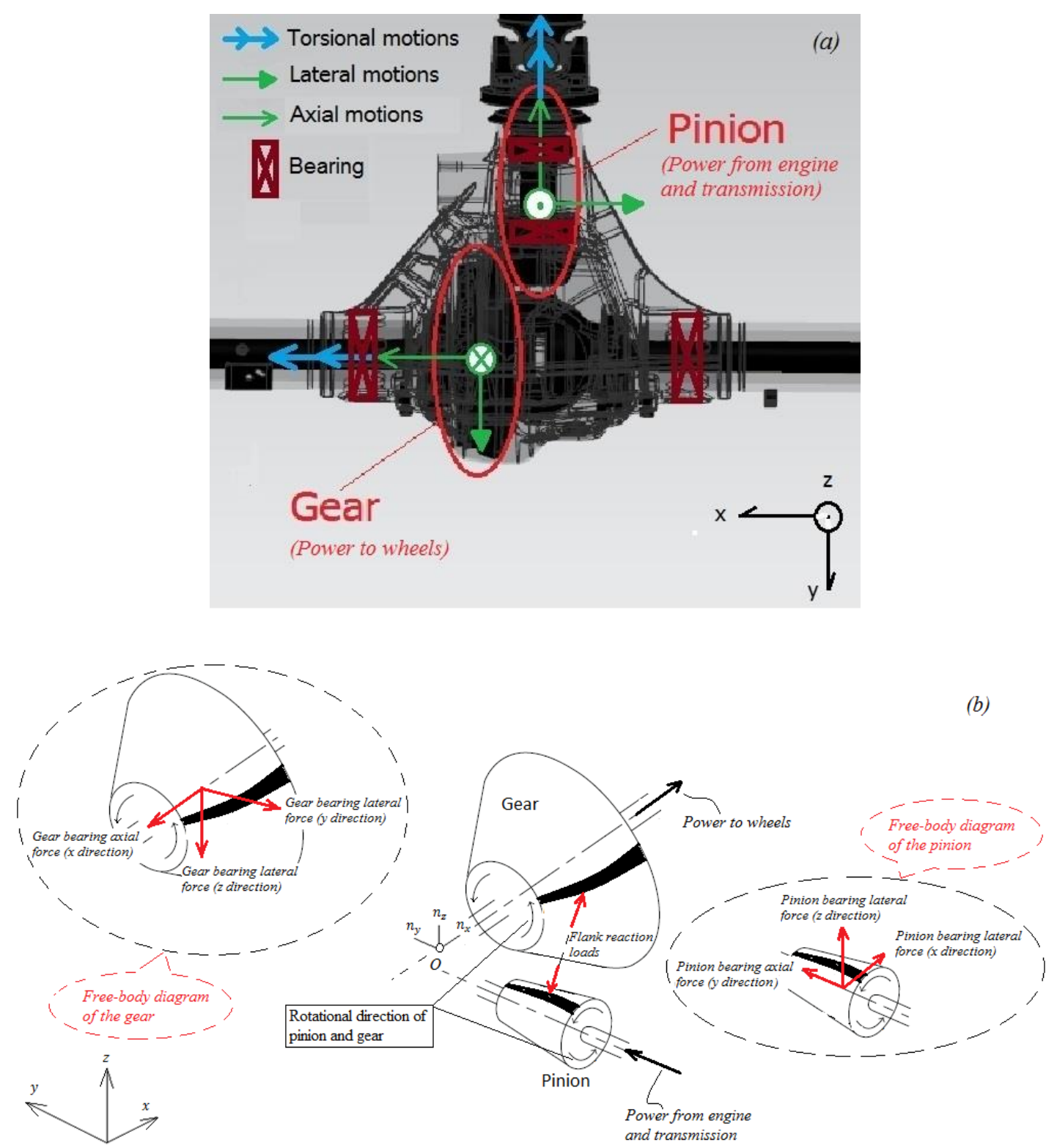

Figure 1. (a) The multi-body dynamics model and (b) The corresponding free body diagrams

Table 1. Inertia/mass properties

\begin{tabular}{|c|c|c|c|}
\hline Part number & Part name & Inertia [kg $\mathbf{~ m}^{\mathbf{2}}$ ] & Mass [kg] \\
\hline 1 & Ground & ----- & ----- \\
\hline 2 & Pinion & $173410^{-6}$ & 12 \\
\hline 3 & Gear & $5.8110^{-2}$ & 49.9 \\
\hline
\end{tabular}

The equations of motion are obtained in the following form:

$$
[M] \ddot{X}+[C] \dot{X}+[K] X=F
$$

where mass $[\mathrm{M}]$, damping $[\mathrm{C}]$ and stiffness $[\mathrm{K}]$ matrices are: 
$[\mathrm{M}]=\left[\begin{array}{cccccccc}I_{p} & 0 & 0 & 0 & 0 & 0 & 0 & 0 \\ 0 & I_{g} & 0 & 0 & 0 & 0 & 0 & 0 \\ 0 & 0 & m_{p} & 0 & 0 & 0 & 0 & 0 \\ 0 & 0 & 0 & m_{p} & 0 & 0 & 0 & 0 \\ 0 & 0 & 0 & 0 & m_{p} & 0 & 0 & 0 \\ 0 & 0 & 0 & 0 & 0 & m_{g} & 0 & 0 \\ 0 & 0 & 0 & 0 & 0 & 0 & m_{g} & 0 \\ 0 & 0 & 0 & 0 & 0 & 0 & 0 & m_{g}\end{array}\right]$

$[\mathrm{C}]=\left[\begin{array}{cccccccc}R_{p} c_{m} R_{p} & -R_{p} c_{m} R_{g} & n_{x} c_{m} R_{p} & n_{y} c_{m} R_{p} & n_{z} c_{m} R_{p} & -n_{x} c_{m} R_{p} & -n_{y} c_{m} R_{p} & -n_{z} c_{m} R_{p} \\ -R_{g} c_{m} R_{p} & R_{g} c_{m} R_{g} & -n_{x} c_{m} R_{g} & -n_{y} c_{m} R_{g} & -n_{z} c_{m} R_{g} & n_{x} c_{m} R_{g} & n_{y} c_{m} R_{g} & n_{z} c_{m} R_{g} \\ n_{x} c_{m} R_{p} & -n_{x} c_{m} R_{g} & c_{p x}+n_{x} c_{m} n_{x} & n_{x} c_{m} n_{y} & n_{x} c_{m} n_{z} & -n_{x} c_{m} n_{x} & -n_{x} c_{m} n_{y} & -n_{x} c_{m} n_{z} \\ n_{y} c_{m} R_{p} & -n_{y} c_{m} R_{g} & n_{y} c_{m} n_{x} & c_{p y}+n_{y} c_{m} n_{y} & n_{y} c_{m} n_{z} & -n_{y} c_{m} n_{x} & -n_{y} c_{m} n_{y} & -n_{y} c_{m} n_{z} \\ n_{z} c_{m} R_{p} & -n_{z} c_{m} R_{g} & n_{z} c_{m} n_{x} & n_{z} c_{m} n_{y} & c_{p z}+n_{z} c_{m} n_{z} & -n_{z} c_{m} n_{x} & -n_{z} c_{m} n_{y} & -n_{z} c_{m} n_{z} \\ -n_{x} c_{m} R_{p} & n_{x} c_{m} R_{g} & -n_{x} c_{m} n_{x} & -n_{x} c_{m} n_{y} & -n_{x} c_{m} n_{z} & c_{g x}+n_{x} c_{m} n_{x} & n_{x} c_{m} n_{y} & n_{x} c_{m} n_{z} \\ -n_{y} c_{m} R_{p} & n_{y} c_{m} R_{g} & -n_{y} c_{m} n_{x} & -n_{y} c_{m} n_{y} & -n_{y} c_{m} n_{z} & n_{y} c_{m} n_{x} & c_{g y}+n_{y} c_{m} n_{y} & n_{y} c_{m} n_{z} \\ -n_{z} c_{m} R_{p} & n_{z} c_{m} R_{g} & -n_{z} c_{m} n_{x} & -n_{z} c_{m} n_{v} & -n_{z} c_{m} n_{z} & n_{z} c_{m} n_{x} & n_{z} c_{m} n_{y} & c_{g z}+n_{z} c_{m} n_{z}\end{array}\right]$

$[\mathrm{K}]=$

$\left[\begin{array}{cccccccc}R_{p} k_{m} R_{p} & -R_{p} k_{m} R_{g} & n_{x} k_{m} R_{p} & n_{y} k_{m} R_{p} & n_{z} k_{m} R_{p} & -n_{x} k_{m} R_{p} & -n_{y} k_{m} R_{p} & -n_{z} k_{m} R_{p} \\ -R_{g} k_{m} R_{p} & R_{g} k_{m} R_{g} & -n_{x} k_{m} R_{g} & -n_{y} k_{m} R_{g} & -n_{z} k_{m} R_{g} & n_{x} k_{m} R_{g} & n_{y} k_{m} R_{g} & n_{z} k_{m} R_{g} \\ n_{x} k_{m} R_{p} & -n_{x} k_{m} R_{g} & k_{p x}+n_{x} k_{m} n_{x} & n_{x} k_{m} n_{y} & n_{x} k_{m} n_{z} & -n_{x} k_{m} n_{x} & -n_{x} k_{m} n_{y} & -n_{x} k_{m} n_{z} \\ n_{y} k_{m} R_{p} & -n_{y} k_{m} R_{g} & n_{y} k_{m} n_{x} & k_{p y}+n_{y} k_{m} n_{y} & n_{y} k_{m} n_{z} & -n_{y} k_{m} n_{x} & -n_{y} k_{m} n_{y} & -n_{y} k_{m} n_{z} \\ n_{z} k_{m} R_{p} & -n_{z} k_{m} R_{g} & n_{z} k_{m} n_{x} & n_{z} k_{m} n_{y} & k_{p z}+n_{z} k_{m} n_{z} & -n_{z} k_{m} n_{x} & -n_{z} k_{m} n_{y} & -n_{z} k_{m} n_{z} \\ -n_{x} k_{m} R_{p} & n_{x} k_{m} R_{g} & -n_{x} k_{m} n_{x} & -n_{x} k_{m} n_{y} & -n_{x} k_{m} n_{z} & k_{g x}+n_{x} k_{m} n_{x} & n_{x} k_{m} n_{y} & n_{x} k_{m} n_{z} \\ -n_{y} k_{m} R_{p} & n_{y} k_{m} R_{g} & -n_{y} k_{m} n_{x} & -n_{y} k_{m} n_{y} & -n_{y} k_{m} n_{z} & n_{y} k_{m} n_{x} & k_{g y}+n_{y} k_{m} n_{y} & n_{y} k_{m} n_{z} \\ -n_{z} k_{m} R_{p} & n_{z} k_{m} R_{g} & -n_{z} k_{m} n_{x} & -n_{z} k_{m} n_{v} & -n_{z} k_{m} n_{z} & n_{z} k_{m} n_{x} & n_{z} k_{m} n_{y} & k_{g z}+n_{z} k_{m} n_{z}\end{array}\right]$

The position vector $[\mathrm{X}]$ and excitation vector $[\mathrm{F}]$ are:

$[\mathrm{X}]=\left[\begin{array}{c}\varphi_{p} \\ \varphi_{g} \\ x_{p x} \\ x_{p y} \\ x_{p z} \\ x_{g x} \\ x_{g y} \\ x_{g z}\end{array}\right], \quad[\mathrm{F}]=\left[\begin{array}{c}T_{p} \\ -T_{g} \\ 0 \\ 0 \\ 0 \\ 0 \\ 0 \\ 0\end{array}\right]$

$c_{m}$ is the structural torsional damping coefficient. $k_{m}(t)$ is the meshing stiffness obtained through TCA (exhibiting non-linear dependence on the applied load), which is introduced to the system dynamics as a Fourier series with the teeth meshing period being the fundamental period of the series $[36,37]$. In fact a map of meshing stiffness Fourier coefficients is provided to the model by means of the CALYX software, arising from the calculations for different loading conditions [20]. The form of the Fourier function is presented in Appendix 1. $n_{x}(t), n_{y}(t)$ and $n_{z}(t)$ are components of the instantaneous unit vectors in the direction of the line of action (also obtained using TCA and employed in the model as Fourier series). This normal vector varies from point to point and with the pinion angle of rotation. $R_{p}(t)$ and $R_{g}(t)$ are the instantaneous radii of contact for the pinion and the gear, respectively, which are defined at every point of 
contact as well. They are also calculated through TCA and introduced in the dynamics model as Fourier series. Therefore, all these terms are time (pinion angle) variants. The general form of the Fourier series expression for these variables is:

$f(t)=\frac{a_{0}}{2}+\sum_{n=1}^{\infty}\left[a_{n} \cos \left(n \varphi_{p}\right)+b_{n} \sin \left(n \varphi_{p}\right)\right]$.

These functions are represented with respect to pinion angle of rotation, using the teeth meshing period as the fundamental period for the series. The exact forms of these Fourier functions are presented in Appendix 1 for the case study examined. The remaining damping and stiffness coefficients are described in the following sections.

The model can be reduced to seven degrees of freedom, after eliminating the rigid body torsional mode [37]. The procedure is explained briefly here. Both sides of the first equation of motion are multiplied by $\frac{R_{p}(t)}{I_{p}}$; the second equation is multiplied by $\frac{R_{g}(t)}{I_{g}}$. After subtracting these two, a new equation of motion is obtained. Thus, the equations of motion of the seven degree-of-freedom reduced system comprise the following matrices (the general form of equations of motion is similar to the set of equations (1)):

$$
\begin{aligned}
{[M] } & =\left[\begin{array}{ccccccc}
m & -n_{x} m & -n_{y} m & -n_{z} m & n_{x} m & n_{y} m & n_{z} m \\
-n_{x} m & m_{p}+n_{x}{ }^{2} m & n_{y} n_{x} m & n_{z} n_{x} m & -n_{x} n_{x} m & -n_{y} n_{x} m & -n_{z} n_{x} m \\
-n_{y} m & n_{x} n_{y} m & m_{p}+n_{y}{ }^{2} m & n_{z} n_{y} m & -n_{x} n_{y} m & -n_{y} n_{y} m & -n_{z} n_{y} m \\
-n_{z} m & n_{x} n_{z} m & n_{y} n_{z} m & m_{p}+n_{z}{ }^{2} m & -n_{x} n_{z} m & -n_{y} n_{z} m & -n_{z} n_{z} m \\
n_{x} m & -n_{x} n_{x} m & -n_{y} n_{x} m & -n_{z} n_{x} m & m_{g}+n_{x}{ }^{2} m & n_{y} n_{x} m & n_{z} n_{x} m \\
n_{y} m & -n_{x} n_{y} m & -n_{y} n_{y} m & -n_{z} n_{y} m & n_{x} n_{y} m & m_{g}+n_{y}{ }^{2} m & n_{z} n_{y} m \\
n_{z} m & -n_{x} n_{z} m & -n_{y} n_{z} m & -n_{z} n_{z} m & n_{x} n_{z} m & n_{y} n_{z} m & m_{g}+n_{z}{ }^{2} m
\end{array}\right] \\
{[C] } & =\left[\begin{array}{ccccccc}
c_{m} & 0 & 0 & 0 & 0 & 0 & 0 \\
0 & c_{p x} & 0 & 0 & 0 & 0 & 0 \\
0 & 0 & c_{p y} & 0 & 0 & 0 & 0 \\
0 & 0 & 0 & c_{p z} & 0 & 0 & 0 \\
0 & 0 & 0 & 0 & c_{g x} & 0 & 0 \\
0 & 0 & 0 & 0 & 0 & c_{g y} & 0 \\
0 & 0 & 0 & 0 & 0 & 0 & c_{g z}
\end{array}\right] \\
{[K] } & =\left[\begin{array}{cccccccc}
k_{m} & 0 & 0 & 0 & 0 & 0 & 0 \\
0 & k_{p x} & 0 & 0 & 0 & 0 & 0 \\
0 & 0 & k_{p y} & 0 & 0 & 0 & 0 \\
0 & 0 & 0 & k_{p z} & 0 & 0 & 0 \\
0 & 0 & 0 & 0 & k_{g x} & 0 & 0 \\
0 & 0 & 0 & 0 & 0 & k_{g y} & 0 \\
0 & 0 & 0 & 0 & 0 & 0 & k_{g z}
\end{array}\right]
\end{aligned}
$$


$[X]=\left[\begin{array}{c}f(x) \\ x_{p x} \\ x_{p y} \\ x_{p z} \\ x_{p x} \\ x_{p y} \\ x_{p z}\end{array}\right], \quad[F]=\left[\begin{array}{c}F^{\prime} \\ n_{x} F^{\prime} \\ n_{y} F^{\prime} \\ n_{z} F^{\prime} \\ -n_{x} F^{\prime} \\ -n_{y} F^{\prime} \\ -n_{z} F^{\prime}\end{array}\right]$

where $m$ is the equivalent mass in the direction of the line of action:

$$
m=\frac{I_{p} I_{g}}{I_{p} R_{g}^{2}+I_{g} R_{p}^{2}}
$$

and following simplification, $F^{\prime}$ is defined as:

$$
F^{\prime}=m\left[\frac{R_{p} T_{p}}{I_{p}}+\frac{R_{g} T_{g}}{I_{g}}-\ddot{e}(t)\right]
$$

$x$ denotes the teeth relative displacement along the instantaneous line of approach between the engaged teeth pairs. This is the Dynamic Transmission Error (DTE), hence:

$$
x(t)=\int_{0}^{t} R_{p} \dot{\varphi_{p}} d t-\int_{0}^{t} R_{g} \dot{\varphi_{g}} d t-U_{g}+U_{p}-e(t)
$$

where

$$
U_{g}-U_{p}=n_{x} x_{g x}+n_{y} x_{g y}+n_{z} x_{g z}-n_{x} x_{p x}-n_{y} x_{p y}-n_{z} x_{p z}
$$

$U_{g}-U_{p}$ represents the contribution of the supporting bearing deflections (lateral and axial motions) in DTE along the instantaneous line of action. These depend on the bearing specifications (stiffness, number of rolling elements etc.), as well as loading that originates from the flank meshing point. Equation (4) is an extension of the DTE equation used in [20], where only the torsional degrees of freedom were considered. $e(t)$ represents the static unloaded transmission error, which is also calculated using TCA considering almost zero applied torque and it is introduced in the model as a Fourier series. Its derivatives can be calculated using the series and are introduced in the model (again, the exact definition of the $e(t)$ Fourier function presented in Appendix 1).

In order to take into account the non-linear effects of backlash, the piece-wise linear function $f(x)$ has been introduced: 


$$
f(x)= \begin{cases}x-b, & x \geq b \\ 0, & -b<x<b \\ x+b, & x \leq-b\end{cases}
$$

$b$ is half the total amount of backlash. There are two critical thresholds that represent severe NVH conditions. The first of these is teeth separation leading to single-sided impacts. This condition is defined as a combination of: $x(t)_{\max } \geq b$ and $-b<x(t)_{\min }<b$. The second - even worse condition - is when teeth exhibit double-sided impacts: $x(t)_{\max } \geq b$ and $x(t)_{\min } \leq-b$.

\section{Calculation of damping coefficients:}

In order to determine the contribution of structural damping in the system, the method described in [38] is used. The natural frequencies are obtained by solving the eigen-value problem (where the stiffness matrix is the result of linearization, containing only the constant coefficients of the stiffness Fourier series):

$$
\left(\operatorname{Det}\left([K]-[M] \omega^{2}\right)=0 \quad \text { and }\left([K]-[M] \omega^{2}\right) \hat{x}=\underline{0}\right)
$$

The matrix of the orthonormal eigenvectors $[\Phi]$ can be obtained using the orthogonality conditions $\left([\Phi]^{T}[M][\Phi]=I\right)$. Finally, the damping coefficients are derived using the following expression and assumed damping ratios, according to [12] (3\% in the torsional direction and $2 \%$ in lateral/axial directions):

$$
[\Phi]^{T}[C][\Phi]=[Z]=\left(\begin{array}{ccc}
2 \zeta_{1} \omega_{1} & \cdots & 0 \\
\vdots & \ddots & \vdots \\
0 & \cdots & 2 \zeta_{7} \omega_{7}
\end{array}\right)
$$

It should be noted that in the current study, constant damping ratios are assumed for any degree of freedom as already mentioned above. Using these values and mass/stiffness data (with meshing stiffness being load-dependent), the presented method is utilized to calculate damping coefficients that are implemented in the equations of motion. These take into account the load varying operating conditions.

\section{Bearing stiffness modelling:}

The bearing stiffness is calculated, taking into account the localised Hertzian contact non-linearity [39]. The non-linear relationship between the bearing reaction force (radial and axial directions) and deflection is: 


$$
\frac{F_{a}}{Z J_{a}(\varepsilon) \sin \varphi}=K_{n}(\delta)^{n} \quad \text { and } \quad \frac{F_{r}}{Z J_{r}(\varepsilon) \cos \varphi}=K_{n}(\delta)^{n}
$$

Thus, instead of calculating the stiffness coefficients $\left(k_{p x}, k_{p y}, k_{p z}, k_{g x}, k_{g y}, k_{g z}\right)$ in the radial and axial directions at any time step/iteration, the bearing reactions are determined based on the system dynamics (deflection at the bearing locations). The flank contact load in the lateral and axial directions is the excitation, which leads to bearing deflection and consequently to the non-linear bearing reaction force in the respective direction. This process is subjected to iteration until convergence is achieved for any given time step. In these equations, $J_{a}(\varepsilon)$ and $J_{r}(\varepsilon)$ are the numerically predicted integral values [39]; $n$ is a constant equal to $10 / 9$ for roller bearings and $3 / 2$ for ball bearings; $K_{n}$ is the non-linear stiffness of the inner ring - rolling element bearing - outer ring assembly, which depends on the geometry and material properties; $\delta$ is the maximum bearing deflection along the contact normal vector.

\section{2- Excitation torques}

The excitation $T_{i}(\mathrm{i}=\mathrm{p}, \mathrm{g})$ in torsional directions comprises the applied torques on the pinion and the ring gear, as well as the contribution due to flank friction:

$$
T_{i}=T_{a i}+T_{f r i}
$$

The torque applied on the road wheels includes the rolling friction resistance $\left(R_{r l}\right)$, aerodynamic resisting force $\left(R_{a}\right)$ and any grading load $\left(R_{G}\right)[40]$ :

$$
T_{a g}=r_{t} \sum F=r_{t}\left(R_{a}+R_{r l}+R_{G}\right)
$$

where $r_{t}$ is the laden dynamic tire radius and:

$$
R_{a}=\frac{\rho}{2} C_{D} A_{f} V^{2}, \quad R_{r l}=f_{r l} W
$$

$f_{r l}$ is the coefficient of rolling resistance and $W$ is the vehicle weight. $R_{G}$ is zero for vehicle motion on a flat road (zero grading).

The instantaneous input torque from the engine (on pinion) is defined as [36]:

$$
T_{a p}=\frac{R_{p}}{R_{g}} T_{a g}\left(1+0.1 \cos \left(2 R_{t} \varphi_{p}\right)\right)
$$


where the second term in the brackets accounts for the dominant second engine order harmonic for the 4 cylinder 4-stroke diesel engine [41] considered in the current study.

The friction generated between the engaged gear teeth pairs contributes to the system excitation as an additional internal damping term. A thin elastohydrodynamic lubricant film is assumed between the meshing teeth pairs, which is subject to non-Newtonian viscous shear, supplemented by any asperity interactions (boundary friction as the result of the direct contact of surfaces). Therefore:

$$
T_{f r i}=R_{i} f_{r}
$$

where the flank friction is given by:

$$
f_{r}=f_{v}+f_{b}
$$

$f_{v}$ is the viscous friction with coefficient of $\mu$ and normal load on the flank, $F_{f l}$ :

$$
f_{v}=\mu F_{f l}
$$

An analytical-experimental equation for the calculation of the viscous friction coefficient is used, considering the non-Newtonian behaviour of the lubricant and thermal effects [42]:

$$
\mu=0.87 \alpha \tau_{0}+1.74 \frac{\tau_{0}}{\bar{p}} \ln \left(\frac{1.2}{\tau_{0} h_{c 0}}\left(\frac{2 \dot{K} \eta_{0}}{1+9.6 \zeta}\right)^{1 / 2}\right)
$$

where:

$$
\zeta=\frac{4}{\pi} \frac{\dot{K}}{h_{c 0} / R^{\prime}}\left(\frac{\bar{p}}{E^{\prime} R^{\prime} K^{\prime} \rho^{\prime} c^{\prime} U^{\prime}}\right)^{1 / 2}
$$

To calculate boundary friction $f_{b}$, the method presented by Greenwood and Tripp [43] is used, where a Gaussian distribution of the asperity heights is assumed, with a mean radius of curvature for an asperity summit. Boundary friction comprises non-Newtonian shear of thin films, as well as adhesive elasto-plastic friction of opposing asperities:

$$
f_{b}=\tau_{L 0} A_{a}+\gamma W_{a}
$$


$\gamma$ is analogous to the adhesive coefficient of friction at asperity level junctions and $\tau_{L 0}$ is the lubricant limiting shear stress [42]. A share of the contact load, $W_{a}$, is carried by the asperities and the total asperity contact area, $A_{a}$, thus [43]:

$$
\begin{gathered}
W_{a}=\frac{16 \sqrt{2}}{15} \pi(\xi \beta \sigma)^{2} \sqrt{\frac{\sigma}{\beta}} E^{\prime} A F_{5 / 2}(\lambda) \\
A_{a}=\pi^{2}(\xi \beta \sigma)^{2} A F_{2}(\lambda)
\end{gathered}
$$

According to Greenwood and Tripp [43], the roughness parameter $(\xi \beta \sigma)$ is reasonably constant with values in the range of $0.03-0.05$ for steel surfaces. The ratio $\sigma / \beta$ is a representation of the average asperity slope, in the range of $10^{-4}-10^{-2}$ [44]. In the current study it is assumed that $\sigma_{1}=\sigma_{2}, \xi \beta \sigma=0.055$ and $\sigma / \beta=0.001$.

The statistical functions $F_{2}(\lambda)$ and $F_{5 / 2}(\lambda)$ are expressed as [45]:

$$
\begin{aligned}
& F_{5 / 2}(\lambda)=\left\{\begin{array}{rr}
-0.004 \lambda^{5}+0.057 \lambda^{4}-0.296 \lambda^{3}+0.784 \lambda^{2}-1.078 \lambda+0.617 ; & \text { for } \lambda \leq \lambda_{c r} \\
0 \quad & \text { for } \lambda>\lambda_{c r}
\end{array}\right. \\
& F_{2}(\lambda)=\left\{\begin{array}{rr}
-0.002 \lambda^{5}+0.028 \lambda^{4}-0.173 \lambda^{3}+0.526 \lambda^{2}-0.804 \lambda+0.500 ; & \text { for } \lambda \leq \lambda_{c r} \\
0 \quad & \text { for } \lambda>\lambda_{\text {cr }}
\end{array}\right.
\end{aligned}
$$

$\lambda=\frac{h}{\sigma}$ is the Stribeck's oil film parameter, where $\sigma$ is the composite root mean square roughness of the contiguous surfaces. $\lambda_{c r} \simeq 3$ is the critical film ratio below which mixed regime of lubrication (including asperity interactions) is expected to occur.

The film thickness $h$ is required for friction calculations. This can be obtained using an extrapolated oil film thickness expression for elliptical point contacts with angled lubricant flow entrainment $[28,29]$ :

$$
h_{c 0}^{*}=4.31 U^{* 0.68} G^{* 0.49} W^{* 0.073}\left\{1-\exp \left[-1.23\left(\frac{R_{s}}{R_{e}}\right)^{2 / 3}\right]\right\}
$$

where, the non-dimensional groups are:

$$
W^{*}=\frac{\pi F_{f l}}{2 E_{r} R_{e}^{2}} \quad U^{*}=\frac{\pi \eta_{0} U^{\prime}}{4 E_{r} R_{e}} \quad G^{*}=\frac{2}{\pi}\left(E_{r} \alpha\right) \quad h_{c 0}^{*}=\frac{h_{c 0}}{R_{e}}
$$


and

$$
\frac{1}{R_{e}}=\frac{\cos ^{2} \theta}{R_{z x}}+\frac{\sin ^{2} \theta}{R_{z y}}, \frac{1}{R_{S}}=\frac{\sin ^{2} \theta}{R_{z x}}+\frac{\cos ^{2} \theta}{R_{z y}}
$$

\subsection{Tooth Contact Analysis (TCA)}

The TCA method is described in detail by Litvin and Fuentes [46]. The main points of the approach are briefly described here. The contact load $F_{f l}$ for all the simultaneously meshing gear teeth pairs is calculated and the data obtained include the instantaneous contact radii of curvature of the teeth surfaces, the teeth pair contact stiffness and the static transmission error. The contact load per teeth pair is a function of the dynamic response. However, its distribution among the teeth pairs in simultaneous contact is defined quasi-statically (for an equal amount of the total contact load). A load distribution factor is calculated as a function of the pinion angle (i.e. time) for all teeth contacts. This is the ratio of the applied load $F_{f l}$ on a given flank under consideration to the total transmitted load $F_{t}[21]$ :

$$
l f=\frac{F_{f l}}{F_{t}}
$$

Full details about the face hobbed, lapped hypoid gear pair used in this study are provided in Mohammadpour et al [31].

\section{Results and discussion}

The present work investigates the dynamics of a pair of differential hypoid gears in a light truck with a 4cylinder, 4-stroke diesel engine. A summary of the input parameters and physical properties of the system is provided in Tables 2 - 5 .

Most of the gear NVH phenomena (structure-borne noise effects) usually occur during transient conditions (acceleration/deceleration of the vehicle). Consequently, numerical results for accelerating and decelerating driving conditions are presented in this paper. Variables of particular importance are the DTE and lateral motion of the gear wheels, which are indications of the NVH signature of the assembly, as well as teeth separation phenomena, leading to loss of contact [2]. Furthermore, the variation of force 
transmissibility through the bearings provides the excitation conditions that reach the differential housing.

These induce structure-borne noise from the lightly damped differential housing.

Table 2. Gear pair parameters

\begin{tabular}{|c|c|c|}
\hline Parameter & Pinion & Gear \\
\hline Teeth number & 13 & 36 \\
\hline Facewidth $(\mathrm{mm})$ & 33.851 & 29.999 \\
\hline Face angle & 29.056 & 59.653 \\
\hline Pitch angle & 29.056 & 59.653 \\
\hline Root angle & 29.056 & 59.653 \\
\hline Spiral angle & 45.989 & 27.601 \\
\hline Pitch apex $(\mathrm{mm})$ & -9.085 & 8.987 \\
\hline Face apex $(\mathrm{mm})$ & 1.368 & 10.948 \\
\hline Outer cone distance $(\mathrm{mm})$ & 83.084 & 95.598 \\
\hline Offset $(\mathrm{mm})$ & 24.0000028 & 24 \\
\hline Sense $($ Hand) & Right & Left \\
\hline \multicolumn{2}{|r}{}
\end{tabular}

Table 3. Bearing properties

\begin{tabular}{|c|c|}
\hline Type & Tapered roller bearing $(\boldsymbol{n}=\mathbf{1 0} / \mathbf{9})$ \\
\hline$Z$ (number of rolling elements) & 14 \\
\hline$\varphi$ (Bearing contact angle) & $15^{\circ}$ \\
\hline$K_{n}$ (inner ring - element - outer ring assembly) & $3 \times 10^{8}$ \\
\hline Preload & 0 \\
\hline
\end{tabular}

Table 4. Input operating conditions

\begin{tabular}{|c|c|}
\hline Frontal area & $2.2 \mathrm{~m}^{2}$ \\
\hline Coefficient of rolling resistance & 0.0166 \\
\hline Drag coefficient & 0.33 \\
\hline Air density & $1.22 \mathrm{~kg} / \mathrm{m}^{3}$ \\
\hline Vehicle weight & $1300 \mathrm{~kg}$ \\
\hline Tyre (type) & $195 / 65 \mathrm{R} 16$ \\
\hline
\end{tabular}

Figure 2 depicts the DTE amplitude variation for the nominal case examined (damping ratios of $3 \%$ and $2 \%$ have been used for the torsional/lateral motion, respectively), where the maximum and minimum amplitude values are plotted for accelerating/decelerating vehicle motions. In order to provide a better physical representation of the operating conditions, the corresponding pinion torque during this speed 
sweep is depicted in the appendix 2 (Fig. A1). This is calculated using equations (11) - (13) and the data in table 4.

Table 5. Physical properties of the lubricant and solids

\begin{tabular}{|c|c|}
\hline Pressure viscosity coefficient & $2.38310^{-8}\left[\mathrm{~Pa}^{-1}\right]$ \\
\hline Atmospheric dynamic viscosity & $0.0171[\mathrm{~Pa} . \mathrm{s}]$ \\
\hline Lubricant Eyring shear stress & $2[\mathrm{MPa}]$ \\
\hline Heat capacity of fluid & $0.14\left[\mathrm{~J} / \mathrm{kg}^{\circ} \mathrm{K}\right]$ \\
\hline Thermal conductivity of fluid & $2000\left[\mathrm{~W} / \mathrm{m}^{\circ} \mathrm{K}\right]$ \\
\hline Modulus of elasticity of contacting solids & $210[\mathrm{GPa}]$ \\
\hline Poisson's ratio of contacting solids & 0.3 \\
\hline Density of contacting solids & $7850\left[\mathrm{~kg} / \mathrm{m}^{3}\right]$ \\
\hline Thermal conductivity of contacting solids & $46\left[\mathrm{~W} / \mathrm{m}^{\circ} \mathrm{K}\right]$ \\
\hline Heat capacity of contacting solids & $470\left[\mathrm{~J} / \mathrm{kg}^{\circ} \mathrm{K}\right]$ \\
\hline Surface roughness of solids, $R_{a}$ & $0.5 \mu \mathrm{m}$ \\
\hline
\end{tabular}

A zero DTE value signifies the threshold of teeth separation. The latter can be observed when the meshing frequency is in the region of the system's natural frequencies, which are presented in Table 6 (with the corresponding vehicle speed). The normalised eigenvectors (in the same Table) indicate the dominant DoF in the relevant resonant motion (highlighted in bold): i) the relative rotation of the gear teeth, ii) the pinion lateral DoF $x_{p}$ and iii) the pinion axial DoF $y_{p}$. The corresponding mode shapes for each resonant condition are presented in the insets in Fig. 2. Super-harmonics of the resonant frequencies also appear in the lower intervals of the frequency spectrum.

At the resonant frequency regions the contact pressure fluctuates heavily (diminishing when teeth separation occurs). Figure 3 shows one meshing cycle of the DTE time history for the vehicle speed corresponding to the section A-A of Fig. 2. The pressure peak values are indicated for two locations of the cycle. The relatively low contact pressure is due to the relatively low applied load in section A-A characteristics. This is because of the low tractive resistance at that vehicle speed. The illustrated severe fluctuations are eventually transferred through the supporting bearings, affecting the system's NVH characteristics. When the gear teeth are in continuous contact the pressure fluctuations are reduced, therefore fewer disturbances are transmitted through the meshing gear pair. 


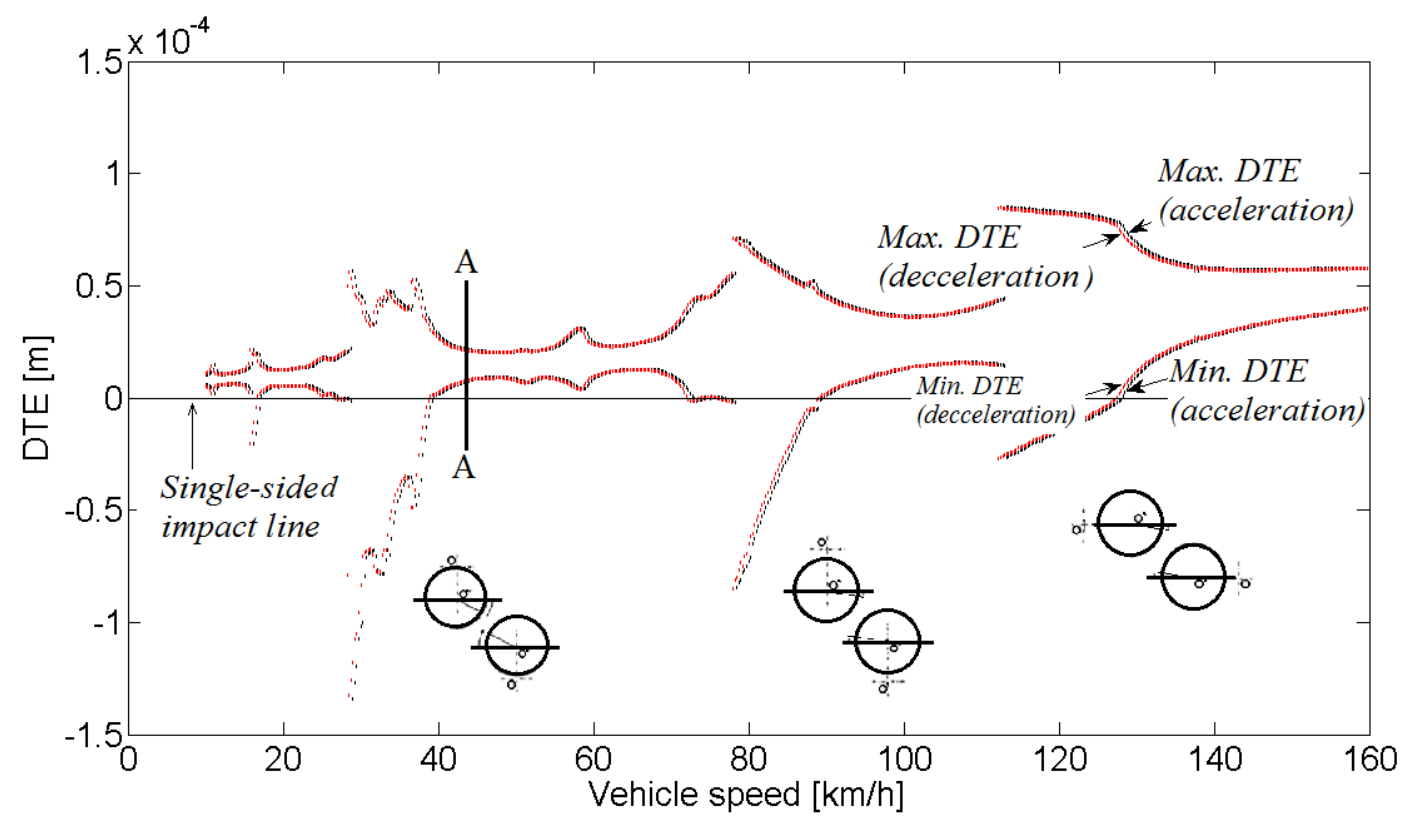

Figure 2. Frequency spectra of the maximum and minimum DTE amplitudes (nominal case)

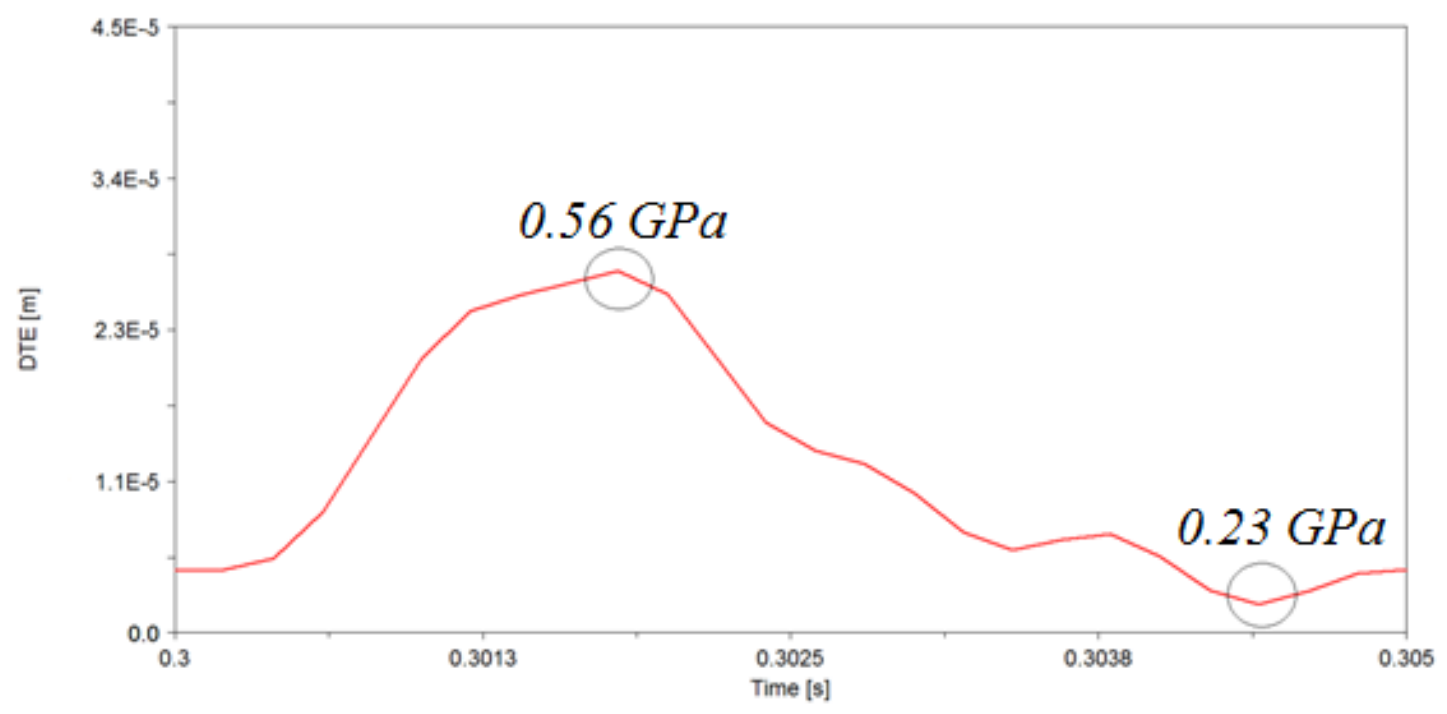

Figure 3. One meshing cycle (time period $=0.005 \mathrm{~s}$ ) of the DTE variation of section A-A (Fig. 2).

In Figure 4, the enlarged views of the first and second resonant regions are presented. It can be clearly seen that activation of the system's non-linearities (gear pair - bearings) induces jump phenomena in the DTE amplitudes, which differ slightly between the decelerating and accelerating motions of the vehicle. Similar behaviour has been observed experimentally $(E)$ and numerically $(N)$ by a number of researchers, such as Yamada et al. [47] (E), Kahraman and Singh [48] (E) for parallel axis gears, Theodossiades and Natsiavas [37] (N) and Cheng and Lim [49] (N) in the case of spur and hypoid gears, 
respectively. The information here is in line with experimental observations related to the axle whine NVH in light trucks [2].

Table 6. Natural frequencies and mode shapes

\begin{tabular}{|c|c|c|c|c|c|c|c|c|}
\hline $\begin{array}{c}\text { Natural } \\
\text { frequencies } \\
{[\mathrm{Hz}]}\end{array}$ & $\begin{array}{c}\text { Equivalent } \\
\text { vehicle speed } \\
{[\mathrm{km} / \mathrm{h}]}\end{array}$ & \multicolumn{6}{|c|}{ Normalised eigenvectors } \\
\hline 166.10 & 32 & $\mathbf{1}$ & 0.173 & 0.004 & 0.208 & -0.031 & -0.001 & -0.039 \\
\hline 415.24 & 80 & 1 & -5.97 & 0.019 & 4.95 & -0.120 & -0.004 & -0.171 \\
\hline 591.72 & 114 & 1 & -0.686 & -368.25 & -0.827 & -0.435 & -0.034 & -1.429 \\
\hline 1100.40 & 212 & 1 & -1.719 & 0.033 & $-\mathbf{- 2 . 0 7 2}$ & -0.168 & -0.006 & -0.269 \\
\hline 2103.12 & 405.2 & 1 & -0.496 & -0.051 & -0.598 & $\mathbf{4 6 . 1 4 7}$ & 0.019 & 0.815 \\
\hline 2453.34 & 472.7 & 1 & -0.602 & -0.141 & -0.726 & -0.686 & $\mathbf{4 . 8 8 7}$ & -1.162 \\
\hline 2888.17 & 556.4 & 1 & -0.594 & -0.126 & -0.716 & -0.736 & 0.288 & $\mathbf{1 2 . 1 2 4}$ \\
\hline
\end{tabular}

A parametric study has been conducted for the effect of damping upon system dynamics. Figure 5 shows the DTE amplitudes, assuming the damping ratios of $1.5 \%$ and $1 \%$ for the torsional and lateral degrees of freedom, respectively [12]. It can clearly be seen (compared with Figure 2) that the maximum/minimum amplitude variations around the resonant regions exhibit stronger fluctuations, which lead to teeth separation, as well as to double-sided impacts in the most severe cases (the threshold for double-sided impacts is $150 \mu \mathrm{m}$, being the total amount of nominal backlash). In addition, the frequency region that teeth separation occurs, occupies a larger vehicle speed range compared with the nominal case. Considering the physics of the investigated gear tribodynamics problem, both structural and lubricant damping, including friction contribute to the behaviour of the real system, absorbing some amounts of energy and consequently, smoothening the system dynamics. It should be noted that with tooth separation, conjunctional friction diminishes. Specifically, significant variations in the differential oil sump temperature conditions (30 - $40^{\circ} \mathrm{C}$ temperature increase) lead to altered $\mathrm{NVH}$ signature, as it has been observed experimentally in [2]. 

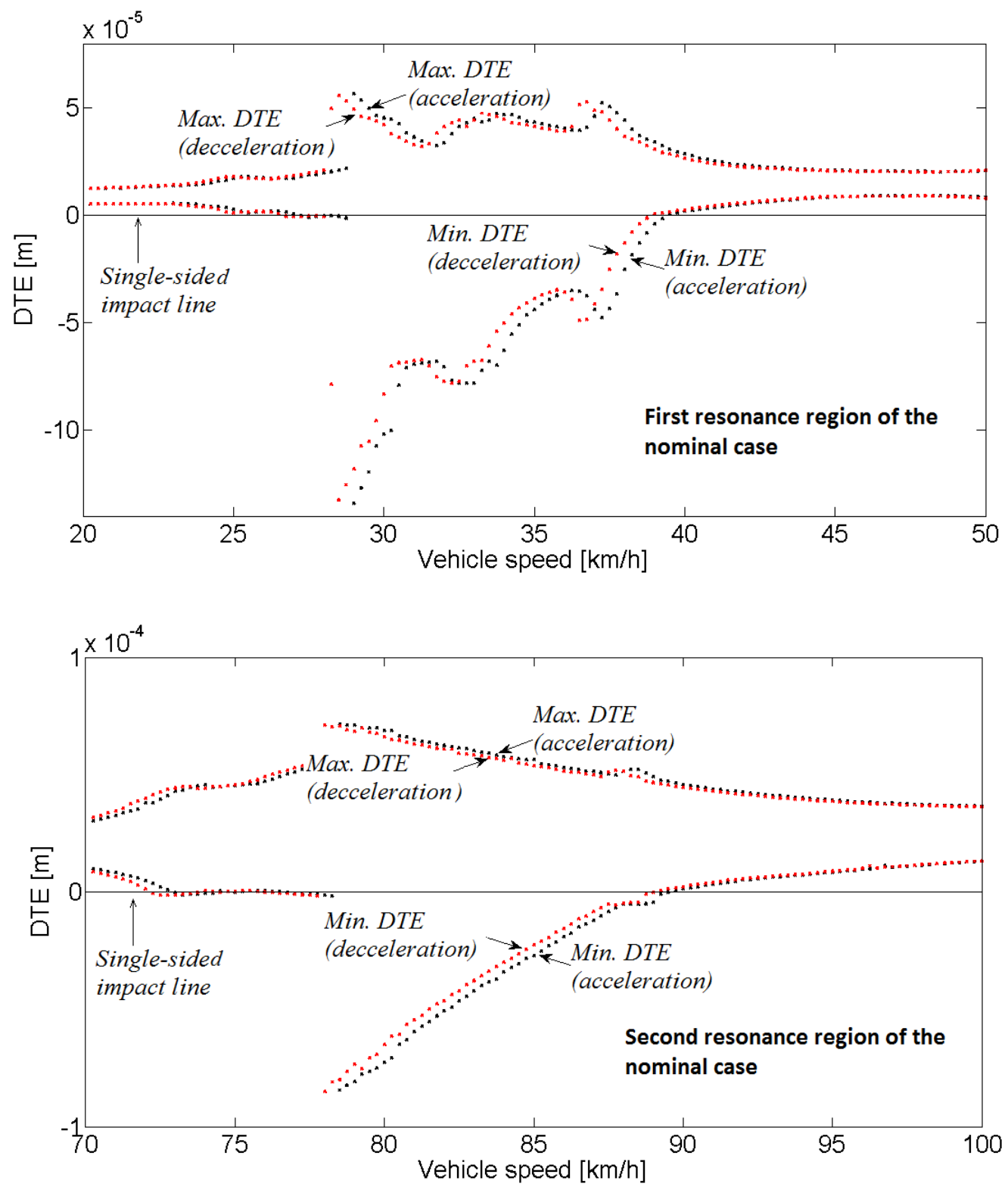

Figure 4. Magnified views of the first and second resonance regions of Figure 2

In order to investigate the effect of supporting bearing rigidity, a study for bearings of higher stiffness has been conducted. Figure 6 shows the DTE amplitude frequency spectra for the case that the bearing inner ring - rolling element - outer ring non-linear stiffness has increased by more than $50 \%\left(K_{n}=8 \times 10^{8}\right)$. All other parameters are kept constant as for the nominal case. As it can be seen, the stiffer bearings lead to more extensive teeth separation conditions (compared with the nominal case) in the vicinity of the second natural frequency, where the pinion lateral motion is dominant. This behaviour is closely related to worsening NVH performance (with teeth separation events lasting longer during the phases of acceleration 
and deceleration). Additionally, severe double-sided impact events also take place for longer periods of time.

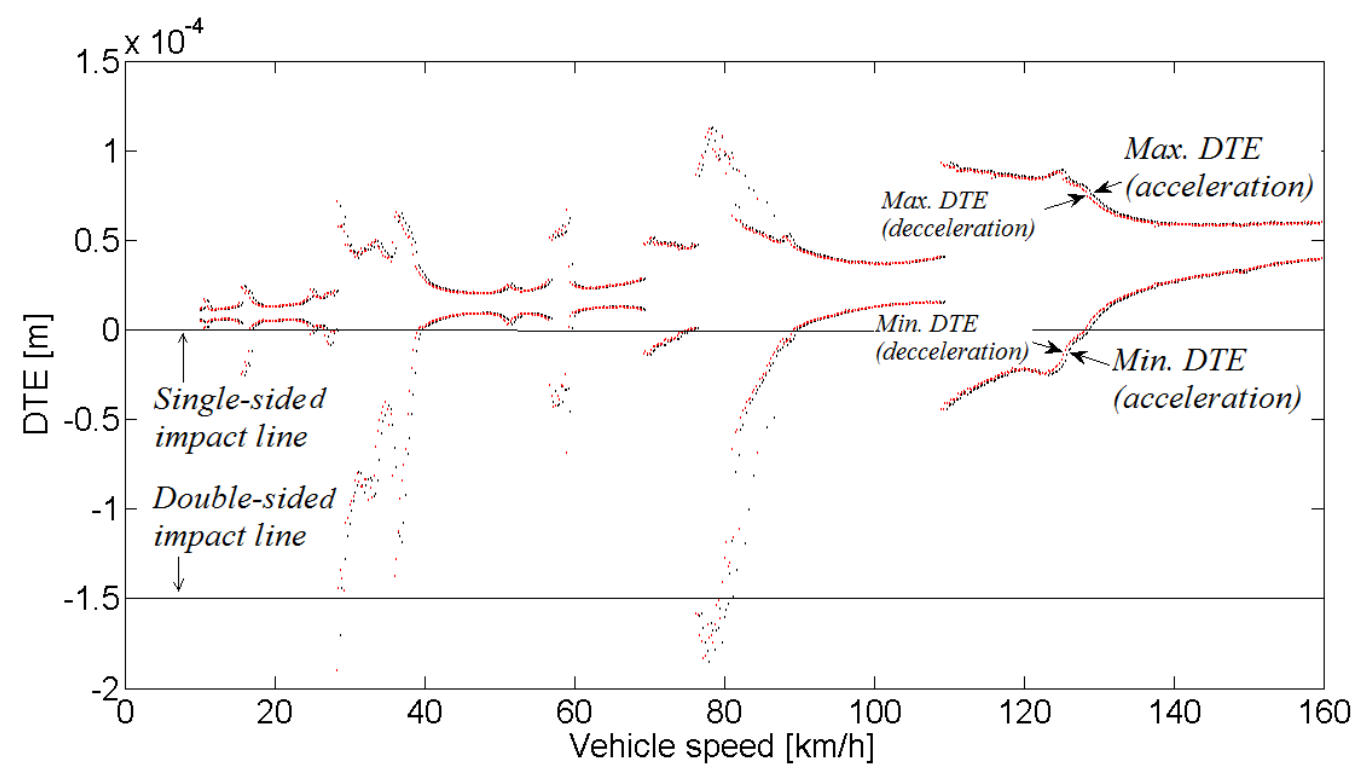

Figure 5. Frequency spectra of the maximum and minimum DTE amplitudes (low damping)

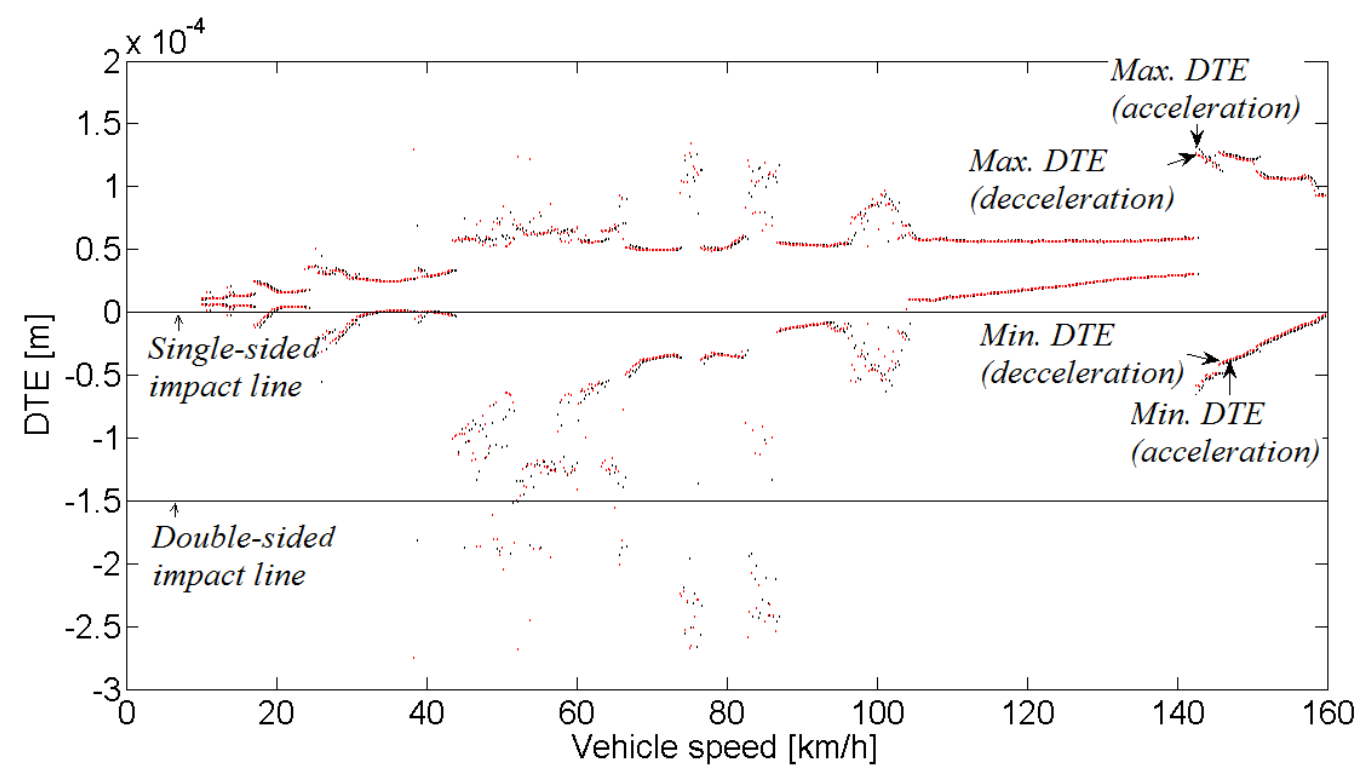

Figure 6. Frequency spectra of the maximum and minimum DTE amplitudes (high bearing stiffness)

A comparison of the system dynamics to those of a gear pair with rotational degrees of freedom only is established through Figure 7, where the DTE amplitude frequency spectra are presented for the simplified model. Damping ratio of $3 \%$ has been assumed, as for the nominal case. It can be seen that apart from the resonant region, the simplified model gives similar results to those of a system with higher bearing 
stiffness. This is an expected observation, since the purely torsional model does not allow for the same amount of energy release (in additional directions), as the model with more degrees of freedom. Nevertheless, the reduced model fails to predict double-sided impacts which occur at resonance. In addition, the torsional model cannot provide any information about the transmitted force for the purpose of any structure-borne noise calculations.

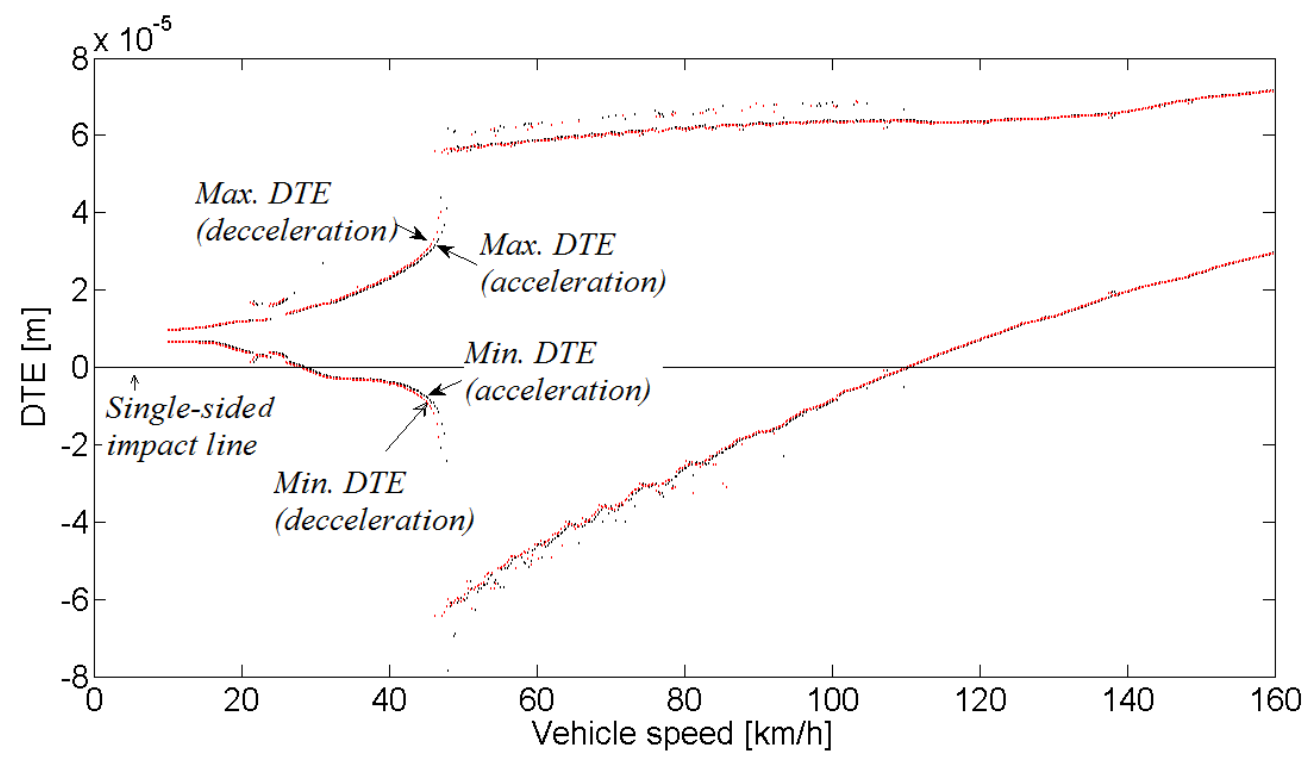

Figure 7. Frequency spectra of the maximum and minimum DTE amplitudes (torsional model)

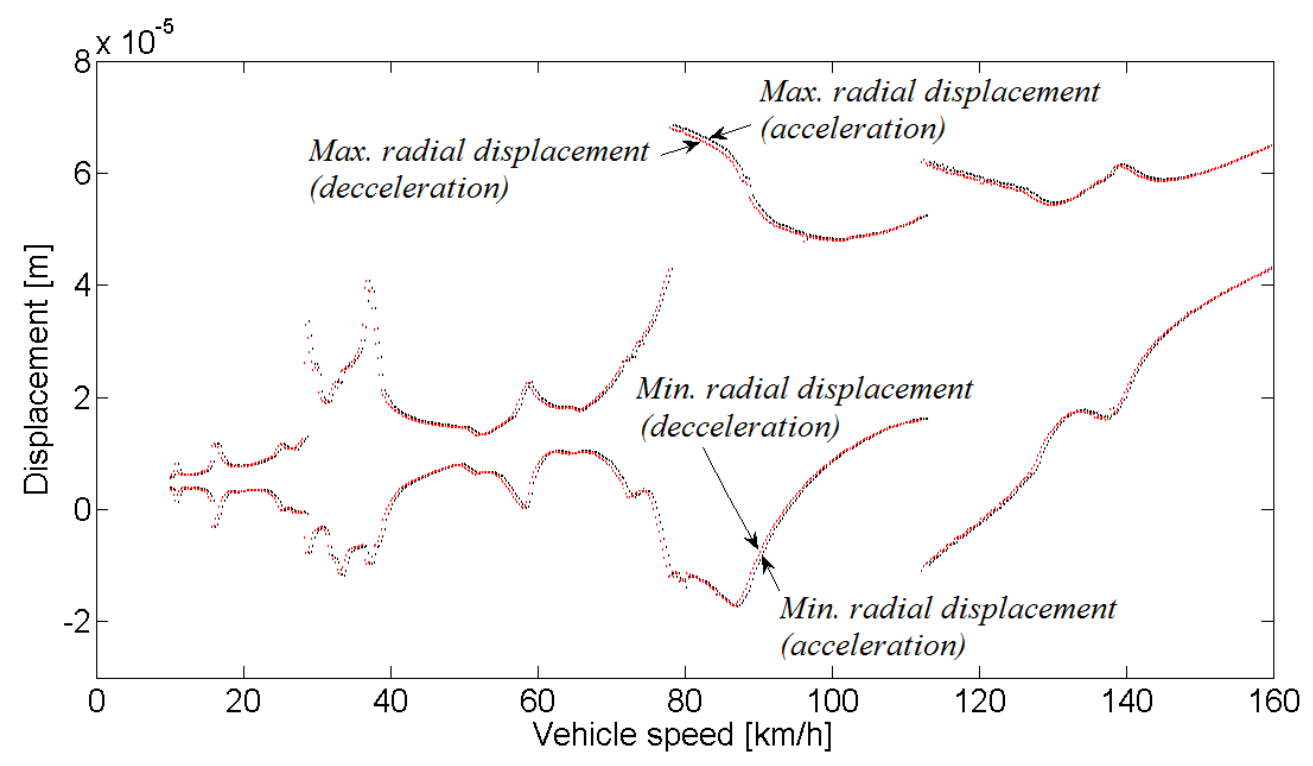

Figure 8. Frequency spectra of the lateral motion maximum and minimum amplitudes (nominal case) 
Figures 8 and 9 exhibit the lateral and axial displacements of the pinion shaft for the nominal case examined. These results generally follow the DTE variation trend. As it can be seen, the bearing is loaded in both directions near resonant frequencies. This action deteriorates the teeth separation conditions, leading to worsening NVH performance and structural excitations transmitted to the differential housing and potentially to the vehicle chassis. An additional observation is that the axial displacement is lower than the lateral motion with high amplitudes in the region of the third resonance only (where the axial motion is dominant in the corresponding mode shape).

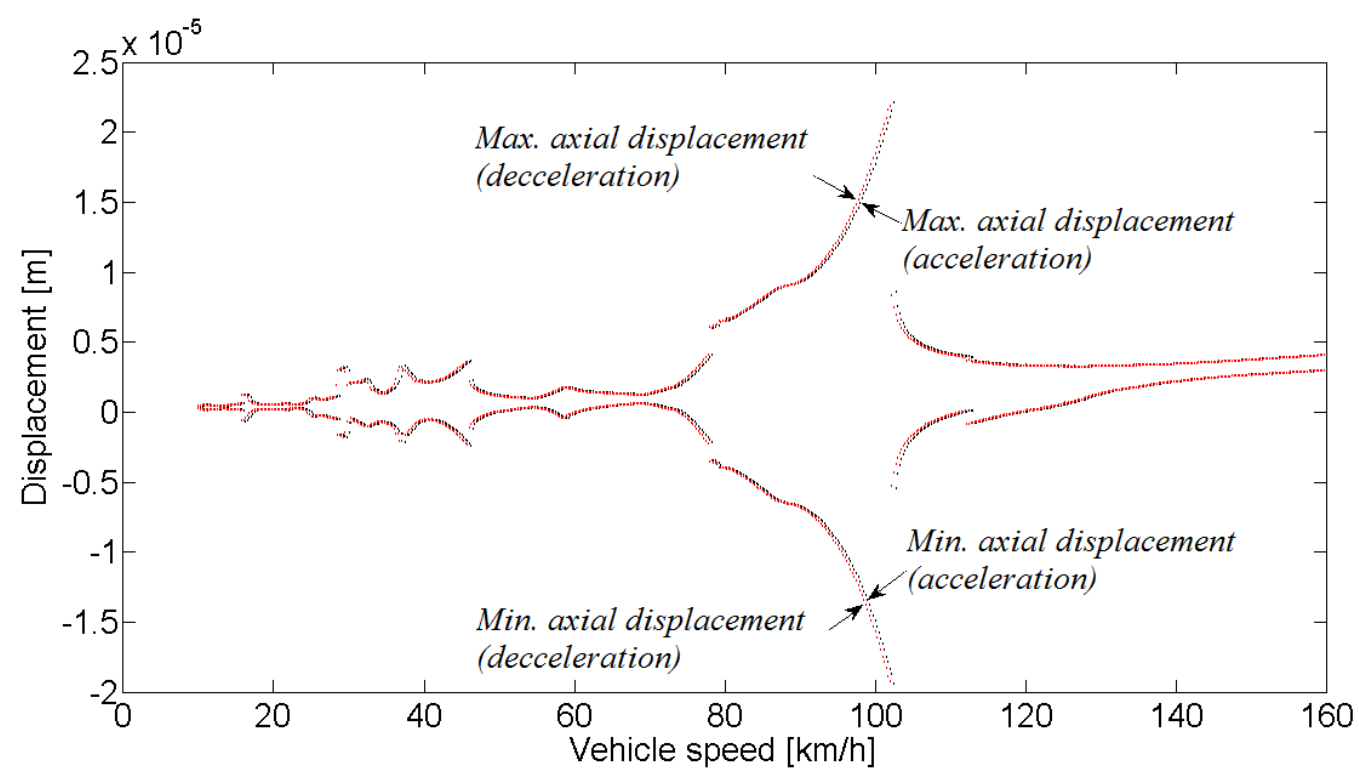

Figure 9. Frequency spectra of the axial motion maximum and minimum amplitudes (nominal case)

An additional important output of the dynamic model is the variation of the transmitted force through the supporting bearings in lateral directions, which is presented in Figures 10 and 11 . The transmitted force $\left(F_{t r}\right)$ has been calculated using equation (9) and the corresponding damping coefficients as:

$$
F_{t r}=F_{t r_{-} \text {stiffness }}+F_{\text {tr_damping }}
$$

The jump phenomena observed in the transmitted force frequency spectra are indicative of the severity that structural vibrations are driven by the excitation conditions during vehicle speed range intervals that coincide with resonances of the system. 
Figure 12 depicts the flank friction torque applied to the pinion. As expected, the graph shows zero torque values during teeth separation, which is observed in the three resonant regions. Furthermore, the peak friction torque values are particularly high near resonance and at relatively low speeds. This is due to predominance of boundary lubrication, which gives higher friction. In order to monitor the frictional losses for a complete meshing cycle, the amount of energy lost is calculated at four different vehicle speeds near/away from resonance (positions A, B, C and D of figure 12), where:

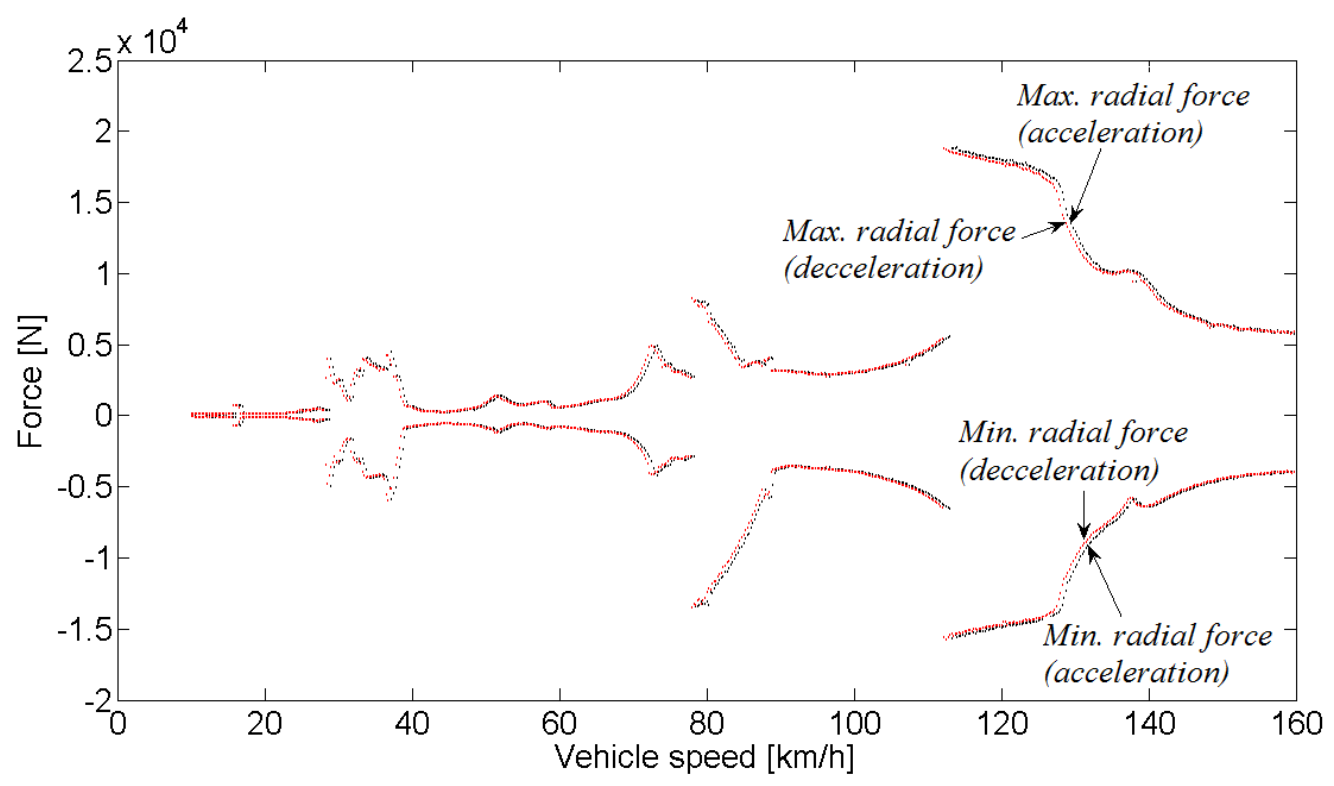

Figure 10. Frequency spectra of the maximum and minimum radial transmitted force amplitudes

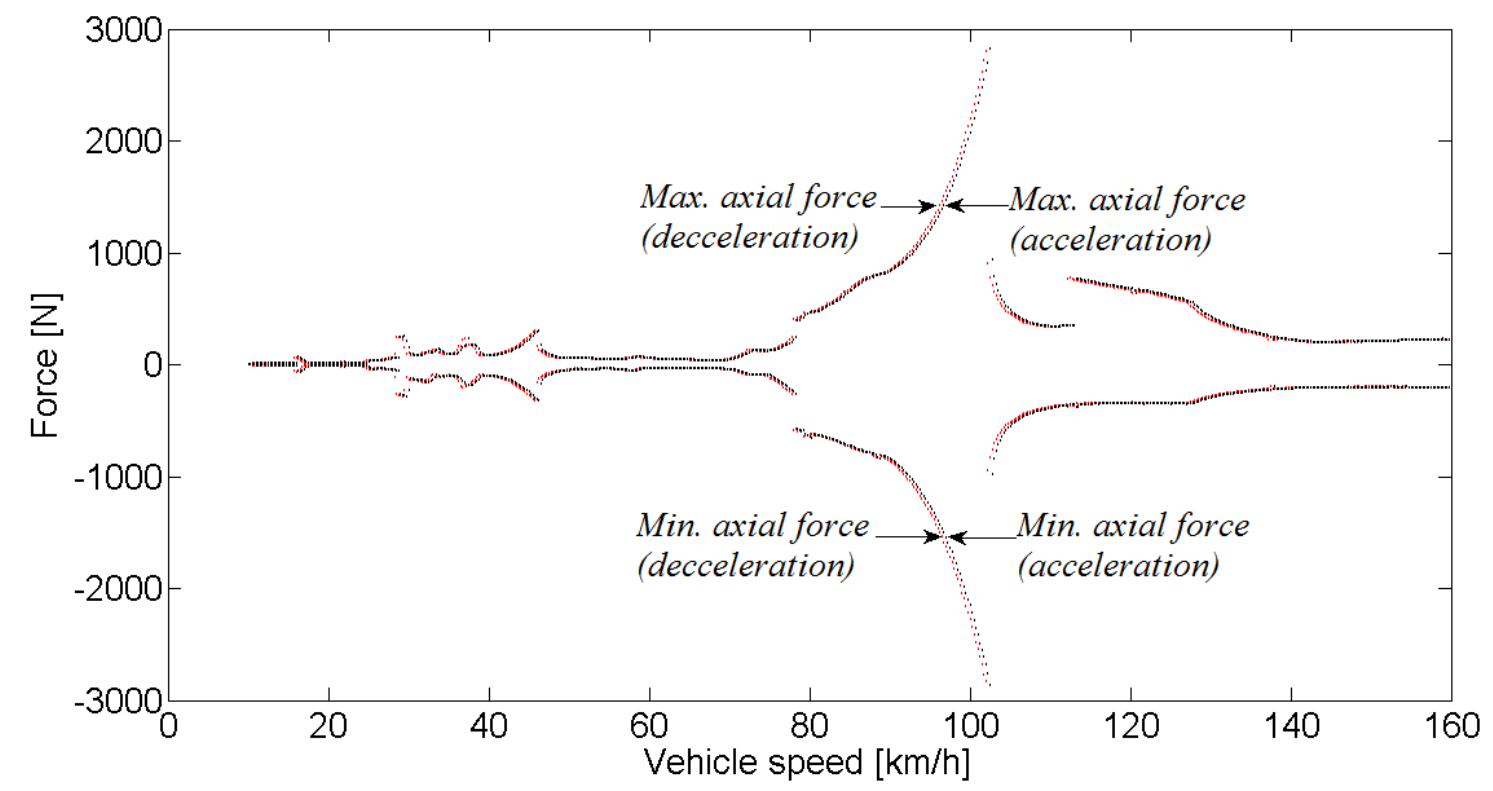

Figure 11. Frequency spectra of the maximum and minimum axial transmitted force amplitudes 


$$
E_{f}=\int_{0}^{\left.\varphi_{p(m e s h} c y c l e\right)} T_{f r p} d \varphi_{p}
$$

The results are presented in Table 7. It can be seen that although the friction torque amplitudes are higher near resonance (positions $B$ and $D$ ), the total loss of energy is reduced when compared with that away from resonance (positions $A$ and $C$ ). Thus, less frictional damping acts near resonance. Figures 13 and 14 exhibit the frictional torque variation on the pinion for one meshing cycle (corresponding to the vehicle speeds at $A$ and $B$, respectively). The friction torque does not exhibit any direction reversals, since in hypoid gears the relative sliding motion between the teeth flanks does not reverse direction when the contact footprint crosses the mean pitch point $[22,49]$. As it can be seen, friction is absent for a significant part of the cycle near resonance because of the teeth contact loss, which explains why less energy is lost in comparison with vehicle speed regions away from resonance.

Table 7. Frictional energy loss

\begin{tabular}{|c|c|c|c|c|}
\hline Vehicle speed & A & B & C & D \\
\hline Frictional energy loss during one meshing cycle (kJ) & 12.75 & 7.37 & 7.15 & 1.58 \\
\hline
\end{tabular}

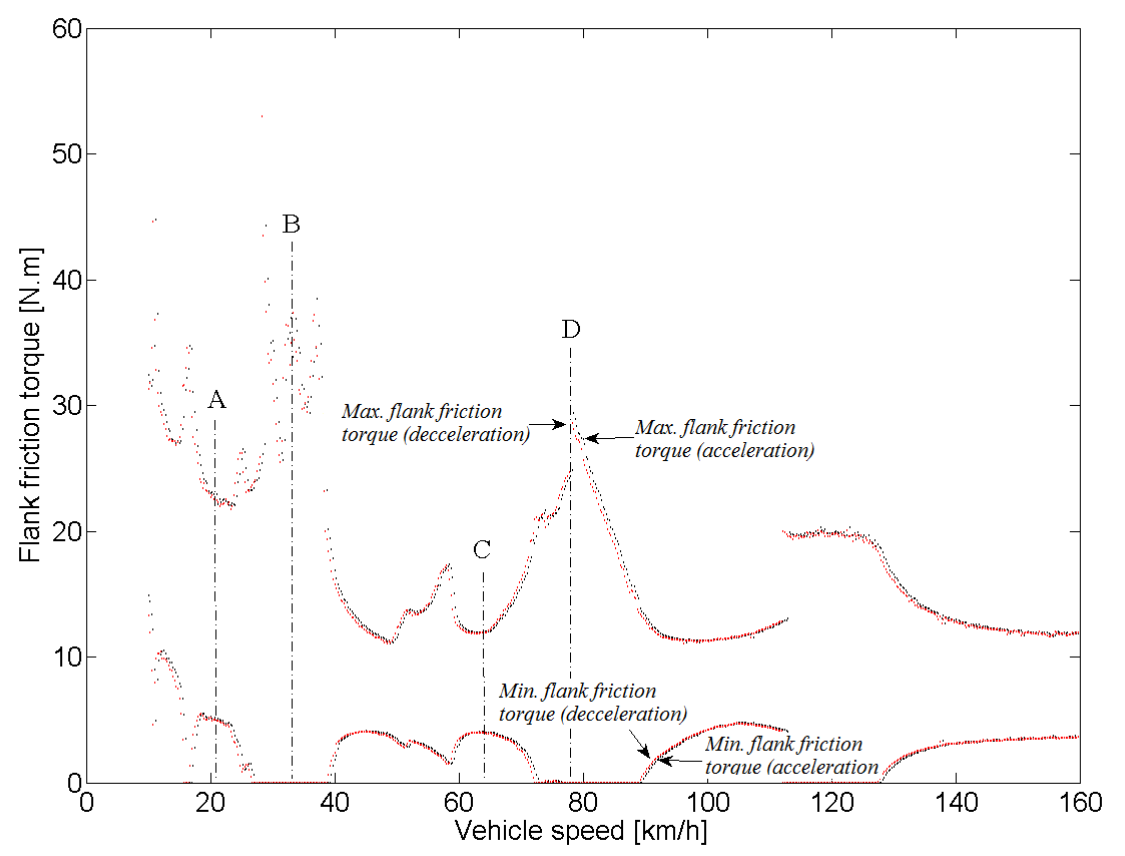

Figure 12. Frequency spectra of the maximum and minimum pinion friction torque. 


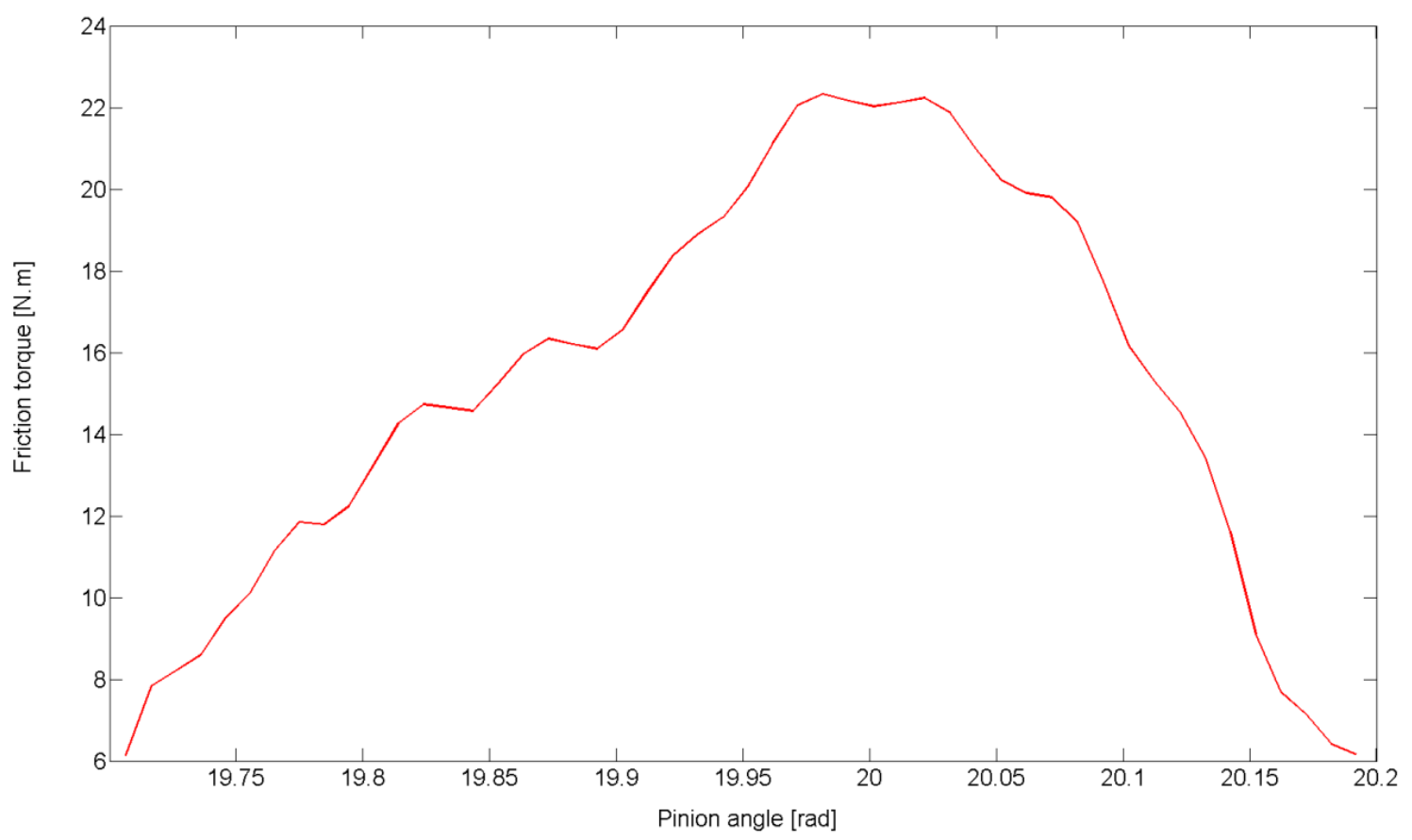

Figure 13. One meshing cycle of the friction torque variation (position A in figure 12)

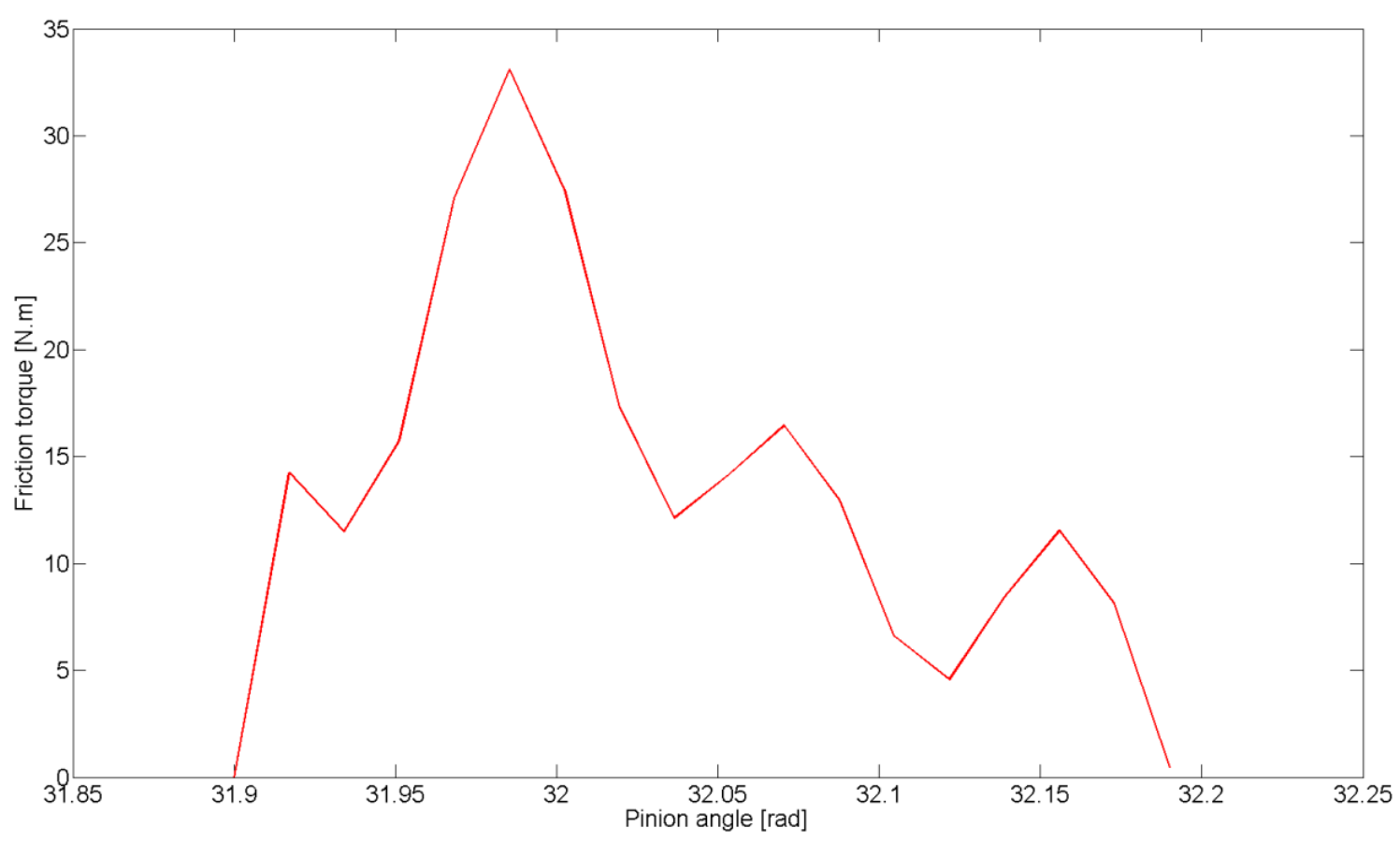

Figure 14. One meshing cycle of the friction torque variation (position B in figure 12)

\section{Concluding remarks}

Efficiency and NVH are two main concerns in hypoid gear pairs. These performance criteria can be estimated at early design stages using numerical models with integrated tribo-dynamics (multi-physics, 
multi-scale analysis). The results have shown that single-sided impacts (teeth separation) can take place around resonant frequencies. With lower system damping, double-sided impacts are also possible during resonant conditions, where system non-linear behaviour is induced. On the other hand, higher supporting bearing rigidity leads to longer teeth separation and severe peak-to-peak DTE values (an indication of worsening NVH). The force transmissibility through the bearings is estimated, indicating strong correlation with modal response in the region of resonance (a key point for axle whine investigations). Finally, friction of meshing teeth pair and the associated energy loss directly affect system dynamics and signature of NVH response. Paradoxically, higher frictional losses can lead to better NVH refinement, a link that can only be ascertained through a detailed tribo-dynamic analysis.

\section{Acknowledgements}

The authors wish to express their gratitude to Dr. Sandeep Vijayakar of Advanced Numerical Solutions Inc. for supplying a licence of the CALYX software and supporting the TCA part of this work.

\section{5- References}

[1] Tangasawi, O., Theodossiades, S. and Rahnejat, H. "Lightly loaded lubricated impacts: Idle gear rattle", Journal of Sound and Vibration, 308(3), 418-430 (2007)

[2] Koronias, G., Theodossiades, S., Rahnejat, H. and Saunders, T. 2011, "Axle whine phenomenon in light trucks: a combined numerical and experimental investigation". Proceedings of the Institution of Mechanical Engineers Part D: Journal of Automobile Engineering, 2011, 225 (7), 885-894.

[3] Ozguven, H. N. and Houser, D. R. 'mathematical models used in gear dynamics- A review', Journal of Sound and Vibration 121 (3), 383-411 (1988)

[4] Kahraman A. and Singh, R. 'interactions between the time varying mesh stiffness and clearance nonlinearities in a geared system', Journal of Sound and Vibration 146 (1), 135-156, (1991) 
[5] Amabili, M. and Rivola, A. 'Dynamic analysis of spur gear pairs: steady-state response and stability of the SDOF model with time varying mesh damping', Mechanical Systems and Signal Processing 11, 375390, (1997)

[6] E.P. Remmers, Dynamics of automotive rear axle gear noise. SAE Paper 710114, (1971)

[7] Kiyono, S., Fujii, Y. and Suzuki, Y. 'Analysis of vibration of bevel gears', Bulletin of the Japan Society of Mechanical Engineers 24, 441-446, (1981)

[8] Abe, E. and Hagiwara, H. 'Advanced Method for Reduction in Axle Gear Noise', Gear Design, Manufacturing and Inspection Manual, Society of Automotive Engineers, 223-236, (1990)

[9] Hirasaka, N., Sugita, H. and Asai, M. 'A simulation method of rear axle gear noise', Journal of Passenger Cars 100, 1383-1387, (1991)

[10] Donley, M.G., Lim, T.C. and Steyer, G.C. 'Dynamic analysis of automotive gearing systems', Journal of Passenger Cars 101, 77 87, (1992)

[11] Cheng, Y. and Lim, T.C. 'Dynamic analysis of high speed hypoid gears with emphasis on automotive axle noise problem', Proceedings of the ASME Power Transmission and Gearing Conference, DETC98/PTG-5784, Atlanta, GA, (1998)

[12] Cheng, Y. and Lim, T.C. 'Dynamics of hypoid gear transmission with time-varying mesh', Proceedings of the ASME Power Transmission and Gearing Conference, DETC2000/PTG-14432, Baltimore, MD, (2000)

[13] Cheng, Y. and Lim, T.C. 'Vibration analysis of hypoid transmissions applying an exact geometry-based gear mesh theory', Journal of Sound and Vibration 240, 519-543, (2001)

[14] Jiang, X. 'Non-linear Torsional Dynamic Analysis of Hypoid Gear Pairs', MSc Thesis, The University of Alabama, (2002)

[15] Wang, H. 'Gear Mesh Characteristics and Dynamics of Hypoid Geared Rotor System', PhD Dissertation. The University of Alabama, (2002)

[16] Wang, J., Lim, T. C. and Li, M. 'Dynamics of a hypoid gear pair considering the effects of time-varying mesh parameters and backlash nonlinearity', Journal of Sound and Vibration, 229 (2), 287-310, (2007)

[17] Dareing, D.W. and Johnson, K.L. "Fluid film damping of rolling contact vibrations", Journal of Mechanical Engineering Science, 17(4), 214-218 (1975) 
[18] Mehdigoli, H., Rahnejat, H. and Gohar, R. "Vibration response of wavy surfaced disc in elastohydrodynamic rolling contact", Wear, 139(1), 1-15 (1990)

[19] Virlez, G., Bruls, O., Duysinx, P. and Poulet, N. "simulation of differentials in four-wheel drive vehicles using multi-body dynamics", ASME, DETC2011. (2011)

[20] Karagiannis, I and Theodossiades, S. "An Alternative Formulation of the Dynamic Transmission Error to Study the Oscillations of Automotive Hypoid Gears", Journal of Vibration and Acoustics, 2013, 136 (12 pages) doi: $10.1115 / 1.4025206$

[21] Xu, H. and Kahraman, A. "Prediction of friction-related power losses of hypoid gear pairs", Proc. Instn. Mech. Engrs, J. Multi-body Dyn., 221, 387-400 (2007)

[22] Kolivand, M., Li, S. and Kahraman, A. "Prediction of mechanical gear mesh efficiency of hypoid gear pairs", Mech. \& Mach. Theory, 45, 1568-1582 (2010)

[23] Snidle, R. W. and Archard, J. F., "Lubrication at elliptical contacts", Proc Instn Mech Engrs., 183, 138$146(1968-69)$

[24] Simon, V., "The influence of misalignments on mesh performances of hypoid gears", Mechanism and Machine Theory, 33, 1277-1291 (1998)

[25] Simon, V., "Influence of Machine Tool Setting Parameters on EHD Lubrication in Hypoid Gears", Mechanism \& Machine Theory, 44, 923-937 (2009)

[26] Ito, N. and Takahashi, K., "Differential Geometrical Conditions of Hypoid Gears with Conjugate Tooth Surfaces", ASME, Journal of Mechanical Design, 122, 323-330, (2000)

[27] Gohar, R. "Oil film thickness and rolling friction in elastohydrodynamic point contact", Trans. ASME, J. Lubn. Tech., 93, (1971)

[28] Chittenden, R. J., Dowson, D., Dunn, J. F. and Taylor, C. M. "A theoretical analysis of the isothermal elastohydrodynamic lubrication of concentrated contacts. I. Direction of lubricant entrainment coincident with the major axis of the Hertzian contact ellipse", Proc. Roy. Soc., Ser. A, 397, 245-269 (1985)

[29] Chittenden, R. J., Dowson, D., Dunn, J. F. and Taylor, C. M. "A theoretical analysis of the isothermal elastohydrodynamic lubrication of concentrated contacts. II. General Case, with lubricant entrainment 
along either principal axis of the Hertzian contact ellipse or at some intermediate angle", Proc. Roy. Soc., Ser. A, 397, 271-294 (1985).

[30] Jalali-Vahid, D., Rahnejat, H., Gohar, R. and Jin, Z.M "Prediction of oil-film thickness and shape in elliptical point contacts under combined rolling and sliding motion", Proc. Instn. Mech. Engrs., J. Engng. Trib., 214, 427-437 (2000)

[31] Mohammadpour, M., Theodossiades, S. and Rahnejat, H. "Elastohydrodynamic lubrication of hypoid gears at high loads", Proc. Instn. Mech. Engrs., Part J: J. Engng. Tribology, 2012, 226 (3), pp. 183-198

[32] De la Cruz, M., W. W. F. Chong, M. Teodorescu, S. Theodossiades, and H. Rahnejat. "Transient mixed thermo-elastohydrodynamic lubrication in multi-speed transmissions." Tribology International 49 (2012): 17-29.

[33] M. Fujii, Y. Nagasaki, and M. Nohara, "Differences in dynamic behavior between straight and skew bevel gears," Transactions of the Japan Society of Mechanical Engineers. Part C, vol. 63, no. 613, pp. 3229-3234, 1997.

[34] Yinong, Li, Li Guiyan, and Zheng Ling. "Influence of asymmetric mesh stiffness on dynamics of spiral bevel gear transmission system." Mathematical Problems in Engineering 2010 (2010).

[35] J. Yang and T. Lim, "Dynamics of Coupled Nonlinear Hypoid Gear Mesh and Time-varying Bearing Stiffness Systems", SAE paper 2011-01-1548

[36] Karagiannis, Y., Theodossiades, S. and Rahnejat, H. "On the dynamics of lubricated hypoid gears", Mechanism \& and Machine Theory, 2012, 48, pp. 94-120

[37] Theodossiades, S. and Natsiavas, S. "On geared rotordynamic systems with oil journal bearings", Journal of sound and vibration, 2001, 243 (4), pp. 721-745.

[38] Caughey, T. K. "Classical normal modes in damped linear dynamic systems", Journal of Applied Mechanics, 1960, 27, p 269-271

[39] Harris, T. and Kotzalas, M. N., Advanced Concepts of Bearing Technology, Taylors and Francis, 2007

[40] Gillespie, T. D. Fundamentals of Vehicle Dynamics, Society of Automotive Engineering, Inc. Pa, USA, 1992 
[41] Rahnejat, H., Multi-body Dynamics: Vehicles, machines and mechanisms, Professional Engineering Publishing, Bury St Edmunds, 1998, ISBN 0768002699

[42] Evans, C. R. and Johnson, K. L. "Regimes of traction in elastohydrodynamic lubrication", Proc. Instn. Mech. Engrs., 1986, 200 (C5), pp. 313-324

[43] Greenwood, J. A. and Tripp, J. H. "The contact of two nominally flat rough surfaces", Proc. Instn. Mech. Engrs, 1970-71. 185, pp. 625-633

[44] Teodorescu, M., Balakrishnan, S. and Rahnejat, H., "Integrated tribological analysis within a multiphysics approach to system dynamics", Tribology and Interface Engineering Series (Elsevier), 48, 2005, pp.725-737

[45] M Mohammadpour, S Theodossiades, H Rahnejat, and P Kelly Transmission efficiency and noise, vibration and harshness refinement of differential hypoid gear pairs Proceedings of the Institution of Mechanical Engineers, Part K: Journal of Multi-body Dynamics 1464419313496559, first published on August 30, 2013 doi:10.1177/1464419313496559

[46] Litvin, F. L. and Fuentes, A. Gear Geometry and Applied Theory, 2nd ed., Cambridge University Press, New York, 2004

[47] T. Yamada and J. Mitsui 1979. A study on the unstable vibration phenomena of a reduction gear system, including the lightly loaded journal bearings, for a marine steam turbine, Bulletin of the JSME, $22,98-106$.

[48] Kahraman, A., and Singh, R., 1990, “Non-Linear Dynamics of a Spur Gear pair" J. Sound Vib., 142(1), pp. $49-75$.

[49] Cheng, Y., and Lim, T. C., 2003, "Dynamics of Hypoid Gear Transmission with Nonlinear Time-Varying Mesh Characteristics," J. Mech. Des., 125(2), pp. 373-382. 


\section{Appendix 1: Definitions of time varying values (Fourier functions extracted from}

TCA)

Fourier function of $\boldsymbol{k}_{m}\left(\varphi_{p}\right)$ :

$$
\begin{aligned}
k_{m}\left(\varphi_{p}\right)=K 0+ & K c 1 * \cos \left(w * \varphi_{p}\right)+K s 1 * \sin \left(w * \varphi_{p}\right)+K c 2 * \cos \left(2 * w * \varphi_{p}\right)+K s 2 * \sin \left(2 * w * \varphi_{p}\right)+K c 3 \\
& * \cos \left(3 * w * \varphi_{p}\right)+K s 3 * \sin \left(3 * w * \varphi_{p}\right)+K c 4 * \cos \left(4 * w * \varphi_{p}\right)+K s 4 * \sin \left(4 * w * \varphi_{p}\right) \\
& +K c 5 * \cos \left(5 * w * \varphi_{p}\right)+K s 5 * \sin \left(5 * w * \varphi_{p}\right)+K c 6 * \cos \left(6 * w * \varphi_{p}\right)+K s 6 * \sin (6 * w \\
& \left.* \varphi_{p}\right)+K c 7 * \cos \left(7 * w * \varphi_{p}\right)+K s 7 * \sin \left(7 * w * \varphi_{p}\right)
\end{aligned}
$$

where:

$w=13$

$K 0\left(T_{p}\right)=5.475 e 7 * T_{p}^{0.3463}$

$K c 1\left(T_{p}\right)=-5.978 * T_{p}{ }^{3}+4.706 e 3 * T_{p}{ }^{2}-8.799 e 5 * T_{p}+7.082 e 6$

$K c 2\left(T_{p}\right)=-3.469 e-1 * T_{p}{ }^{3}+3.1 e 2 * T_{p}{ }^{2}-7.937 e 4 * T_{p}+7.367 e 6$

$K c 3\left(T_{p}\right)=-4.068 e-1 * T_{p}{ }^{3}+2.893 e 2 * T_{p}{ }^{2}-4.481 e 4 * T_{p}-1.152 e 5$

$K c 4\left(T_{p}\right)=-7.227 e-2 * T_{p}{ }^{3}+5.579 e 1 * T_{p}{ }^{2}-9.0 e 3 * T_{p}+3.679 e 5$

$K c 5\left(T_{p}\right)=-2.517 e-2 * T_{p}{ }^{3}+2.047 e 1 * T_{p}{ }^{2}-4.247 e 3 * T_{p}+1.772 e 5$

$K c 6\left(T_{p}\right)=-3.931 e-2 * T_{p}{ }^{3}+3.51 e 1 * T_{p}{ }^{2}-8.36 e 3 * T_{p}+2.374 e 5$

$K c 7\left(T_{p}\right)=-3.331 e-2 * T_{p}{ }^{3}+3.03 e 1 * T_{p}{ }^{2}-7.534 e 3 * T_{p}+4.212 e 5$

$K s 1\left(T_{p}\right)=2.231 * T_{p}{ }^{3}-1.655 e 3 * T_{p}{ }^{2}+2.43 e 5 * T_{p}+5.734 e 6$

$K s 2\left(T_{p}\right)=4.18 e-1 * T_{p}{ }^{3}-2.783 e 2 * T_{p}{ }^{2}+4.254 e 4 * T_{p}-2.384 e 6$

$K s 3\left(T_{p}\right)=2.625 e-1 * T_{p}{ }^{3}-2.084 e 2 * T_{p}{ }^{2}+3.883 e 4 * T_{p}+5.147 e 5$

$K s 4\left(T_{p}\right)=-1.307 e-1 * T_{p}{ }^{3}+9.253 e 1 * T_{p}{ }^{2}-1.296 e 4 * T_{p}-8.178 e 5$

$K s 5\left(T_{p}\right)=7.628 e-2 * T_{p}{ }^{3}-5.397 e 1 * T_{p}{ }^{2}+8.015 e 3 * T_{p}+4.539 e 5$

$K s 6\left(T_{p}\right)=-1.325 e-2 * T_{p}{ }^{3}+7.217 * T_{p}{ }^{2}-4.897 e 2 * T_{p}-3.688 e 5$

$K s 7\left(T_{p}\right)=6.722 e-2 * T_{p}{ }^{3}-4.701 e 1 * T_{p}{ }^{2}+7.315 e 3 * T_{p}-7.315 e 4$

Fourier function of $\mathbf{R}_{\mathbf{p}}\left(\varphi_{p}\right)$ :

$$
\begin{aligned}
R_{p}\left(\varphi_{p}\right)=R p 0+ & R p c 1 * \cos \left(w * \varphi_{p}\right)+R p s 1 * \sin \left(w * \varphi_{p}\right)+R p c 2 * \cos \left(2 * w * \varphi_{p}\right)+R p s 2 * \sin \left(2 * w * \varphi_{p}\right) \\
& +R p c 3 * \cos \left(3 * w * \varphi_{p}\right)+R p s 3 * \sin \left(3 * w * \varphi_{p}\right)+R p c 4 * \cos \left(4 * w * \varphi_{p}\right)+R p s 4 * \sin (4 * w \\
& \left.* \varphi_{p}\right)+R p c 5 * \cos \left(5 * w * \varphi_{p}\right)+R p s 5 * \sin \left(5 * w * \varphi_{p}\right)+R p c 6 * \cos \left(6 * w * \varphi_{p}\right)+R p s 6 \\
& * \sin \left(6 * w * \varphi_{p}\right)+R p c 7 * \cos \left(7 * w * \varphi_{p}\right)+R p s 7 * \sin \left(7 * w * \varphi_{p}\right)
\end{aligned}
$$

where:

$$
\begin{aligned}
w=13 ; R p 0= & 0.01997 ; R p c 1=0.000123 ; R p s 1=3.012 e-5 ; R p c 2=-6.392 e-6 ; R p s 2 \\
& =3.672 e-6 ; R p c 3=-7.768 e-6 ; R p s 3=1.425 e-5 ; R p c 4=-4.872 e-6 ; R p s 4 \\
& =5.674 e-6 ; R p c 5=-2.687 e-6 ; R p s 5=6.229 e-6 ; R p c 6=1.115 e-6 ; R p s 6 \\
& =2.342 e-6 ; R p c 7=1.79 e-6 ; R p s 7=-1.383 e-6 ;
\end{aligned}
$$

Fourier function of $R_{g}\left(\varphi_{p}\right)$ : 


$$
\begin{aligned}
R_{g}\left(\varphi_{p}\right)=R g 0+ & R g c 1 * \cos \left(w * \varphi_{p}\right)+R g s 1 * \sin \left(w * \varphi_{p}\right)+R g c 2 * \cos \left(2 * w * \varphi_{p}\right)+R g s 2 * \sin \left(2 * w * \varphi_{p}\right) \\
& +R g c 3 * \cos \left(3 * w * \varphi_{p}\right)+R g \sin 3 * \sin \left(3 * w * \varphi_{p}\right)+R g c 4 * \cos \left(4 * w * \varphi_{p}\right)+R g s 4 * \sin (4 \\
& \left.* w * \varphi_{p}\right)+R g c 5 * \cos \left(5 * w * \varphi_{p}\right)+R g s 5 * \sin \left(5 * w * \varphi_{p}\right)+R g c 6 * \cos \left(6 * w * \varphi_{p}\right)+R g s 6 \\
& * \sin \left(6 * w * y \varphi_{p}\right)+R g c 7 * \cos \left(7 * w * \varphi_{p}\right)+R g s 7 * \sin \left(7 * w * \varphi_{p}\right)
\end{aligned}
$$

where:

$$
\begin{aligned}
w=13 ; \operatorname{Rg} 0= & 0.05782 ; \operatorname{Rgc} 1=9.27 e-5 ; R g s 1=-2.454 e-5 ; R g c 2=-1.233 e-5 ; R g s 2 \\
& =-5.596 e-6 ; R g c 3=-1.273 e-5 ; R g s 3=5.692 e-6 ; R g c 4=-5.677 e-6 ; R g s 4 \\
& =2.497 e-6 ; R g c 5=-3.142 e-6 ; R g s 5=4.947 e-6 ; R g c 6=5.282 e-8 ; R g s 6 \\
& =3.231 e-6 ; R g c 7=8.631 e-7 ; R g s 7=-4.659 e-7 ;
\end{aligned}
$$

\section{Fourier function of $\boldsymbol{e}\left(\boldsymbol{\varphi}_{\boldsymbol{p}}\right)$ :}

$$
\begin{array}{rl}
e\left(\varphi_{p}\right)=e 0+e c 1 & * \cos \left(w * \varphi_{p}\right)+e s 1 * \sin \left(w * \varphi_{p}\right)+e c 2 * \cos \left(2 * w * \varphi_{p}\right)+e s 2 * \sin \left(2 * w * \varphi_{p}\right)+e c 3 \\
& * \cos \left(3 * w * \varphi_{p}\right)+e s 3 * \sin \left(3 * w * \varphi_{p}\right)+e c 4 * \sin \left(4 * w * \varphi_{p}\right)+e s 4 * \sin \left(4 * w * \varphi_{p}\right)+e c 5 \\
& * \cos \left(5 * w * \varphi_{p}\right)+e s 5 * \sin \left(5 * w * \varphi_{p}\right)+e c 6 * \cos \left(6 * w * \varphi_{p}\right)+e s 6 \sin \left(6 * w * \varphi_{p}\right)+e c 7 \\
& * \cos \left(7 * w * \varphi_{p}\right)+e s 7 * \sin \left(7 * w * \varphi_{p}\right)
\end{array}
$$

where:

$$
\begin{aligned}
& w=13 ; e 0=9.598 e-7 ; \text { ec } 1=-6.634 e-7 ; \text { es } 1=1.532 e-7 ; \text { ec } 2=1.215 e-7 ; \text { es } 2=-1.108 e-7 ; \text { ec } 3 \\
& \quad=-2.445 e-8 ; \text { es } 3=6.357 e-8 ; \text { ec } 4=-2.201 e-9 ; \text { es } 4=-3.548 e-8 ; \text { ec5 } \\
& =8.653 e-9 ; \text { es } 5=1.695 e-8 ; \text { ec } 6=-8.925 e-9 ; \text { es } 6=-5.551 e-9 ; \text { ec } 7 \\
& =3.186 e-9 ; \text { es } 7=7.259 e-9 ;
\end{aligned}
$$

\section{Fourier function of $\boldsymbol{n}_{\boldsymbol{x}}\left(\boldsymbol{\varphi}_{\mathbf{p}}\right)$ :}

$$
\begin{aligned}
n_{x}\left(\varphi_{p}\right)=n x 0+ & n x c 1 * \cos \left(w * \varphi_{p}\right)+n x s 1 * \sin \left(w * \varphi_{p}\right)+n x c 2 * \cos \left(2 * w * \varphi_{p}\right)+n x s 2 * \sin \left(2 * w * \varphi_{p}\right) \\
& +n x c 3 * \cos \left(3 * w * \varphi_{p}\right)+n x s 3 * \sin \left(3 * w * \varphi_{p}\right)+n x c 4 * \sin \left(4 * w * \varphi_{p}\right)+n x s 4 * \sin (4 * w \\
& \left.* \varphi_{p}\right)+n x c 5 * \cos \left(5 * w * \varphi_{p}\right)+n x s 5 * \sin \left(5 * w * \varphi_{p}\right)+n x c 6 * \cos \left(6 * w * \varphi_{p}\right)+n x s 6 \\
& * \sin \left(6 * w * \varphi_{p}\right)+n x c 7 * \cos \left(7 * w * \varphi_{p}\right)+n x s 7 * \sin \left(7 * w * \varphi_{p}\right)
\end{aligned}
$$

where:

$$
\begin{aligned}
w=13 ; n x 0= & -0.6384 ; n x c 1=0.0005148 ; n x s 1=0.001959 ; n x c 2=-0.0002453 ; n x s 2 \\
& =-0.0002076 ; n x c 3=5.931 \mathrm{e}-5 ; n x s 3=0.0001109 ; n x c 4=-2.076 \mathrm{e}-5 ; n x s 4 \\
& =1.633 \mathrm{e}-5 ; n x c 5=-2.017 \mathrm{e}-5 ; n x s 5=-2.095 \mathrm{e}-6 ; n x c 6=2.445 \mathrm{e}-5 ; n x s 6 \\
& =-2.252 \mathrm{e}-5 ; n x c 7=1.952 \mathrm{e}-5 ; n x s 7=-1.722 \mathrm{e}-6 ;
\end{aligned}
$$

\section{Fourier function of $\boldsymbol{n}_{\boldsymbol{y}}\left(\boldsymbol{\varphi}_{\mathbf{p}}\right)$ :}

$$
\begin{aligned}
n_{y}\left(\varphi_{p}\right)=n y 0+ & n y c 1 * \cos \left(w * \varphi_{p}\right)+n y s 1 * \sin \left(w * \varphi_{p}\right)+n y c 2 * \cos \left(2 * w * \varphi_{p}\right)+n y s 2 * \sin \left(2 * w * \varphi_{p}\right) \\
& +n y c 3 * \cos \left(3 * w * \varphi_{p}\right)+n y s 3 * \sin \left(3 * w * \varphi_{p}\right)+n y c 4 * \sin \left(4 * w * \varphi_{p}\right)+n y s 4 * \sin (4 * w \\
& \left.* \varphi_{p}\right)+n y c 5 * \cos \left(5 * w * \varphi_{p}\right)+n y s 5 \sin \left(5 * w * \varphi_{p}\right)+n y c 6 * \cos \left(6 * w * \varphi_{p}\right)+n y s 6 \\
& * \sin \left(6 * w * \varphi_{p}\right)+n y c 7 * \cos \left(7 * w * \varphi_{p}\right)+n y s 7 * \sin \left(7 * w * \varphi_{p}\right)
\end{aligned}
$$

where:

$$
\begin{aligned}
w=13 ; n y 0= & 0.01831 ; \text { nyc } 1=-0.003291 ; \text { nys } 1=-0.002627 ; \text { nyc } 2=-0.001232 ; \text { nys } 2 \\
& =5.879 \mathrm{e}-5 ; \text { nyc3 }=-0.0003643 ; \text { nys } 3=0.0003614 ; \text { nyc4 } 4=7.139 \mathrm{e}-5 ; \text { nys } 4 \\
& =0.000148 ; \text { nyc5 } 5.639 \mathrm{e}-5 ; \text { nys } 5=-0.0001207 ; \text { nyc6 }=-5.86 \mathrm{e}-5 ; \text { nys } 6 \\
& =-0.0001038 ; \text { nyc7 }=-7.847 \mathrm{e}-5 ; \text { nys } 7=3.232 \mathrm{e}-6 ;
\end{aligned}
$$

Fourier function of $\boldsymbol{n}_{\boldsymbol{z}}\left(\boldsymbol{\varphi}_{\mathbf{p}}\right)$ :

$$
\begin{aligned}
n_{z}\left(\varphi_{p}\right)=n z 0+ & n z c 1 * \cos \left(w * \varphi_{p}\right)+n z s 1 * \sin \left(w * \varphi_{p}\right)+n z c 2 * \cos \left(2 * w * \varphi_{p}\right)+n z s 2 * \sin \left(2 * w * \varphi_{p}\right) \\
& +n z c 3 * \cos \left(3 * w * \varphi_{p}\right)+n z s 3 * \sin \left(3 * w * \varphi_{p}\right)+n z c 4 * \sin \left(4 * w * \varphi_{p}\right)+n z s 4 * \sin (4 * w \\
& \left.* \varphi_{p}\right)+n z c 5 * \cos \left(5 * w * \varphi_{p}\right)+n z s 5 * \sin \left(5 * w * \varphi_{p}\right)+n z c 6 * \cos \left(6 * w * \varphi_{p}\right)+n z s 6 \\
& * \sin \left(6 * w * \varphi_{p}\right)+n z c 7 * \cos \left(7 * w * \varphi_{p}\right)+n z s 7 * \sin \left(7 * w * \varphi_{p}\right)
\end{aligned}
$$


where:

$$
\begin{aligned}
w=13 ; n z 0= & -0.7695 ; n z c 1=-0.0005033 ; n z s 1=-0.00169 ; n z c 2=0.0001738 ; n z s 2 \\
& =0.0001789 ; n z c 3=-5.524 \mathrm{e}-5 ; n z s 3=-8.202 \mathrm{e}-5 ; n z c 4=2.077 \mathrm{e}-5 ; n z s 4 \\
& =-9.466 \mathrm{e}-6 ; n z c 5=1.898 \mathrm{e}-5 ; n z s 5=-1.916 \mathrm{e}-6 ; n z c 6=-2.19 \mathrm{e}-5 ; n z s 6 \\
& =1.593 \mathrm{e}-5 ; n z c 7=-1.805 \mathrm{e}-5 ; n z s 7=1.92 \mathrm{e}-6 ;
\end{aligned}
$$

\section{Appendix 2: Input torque variations}

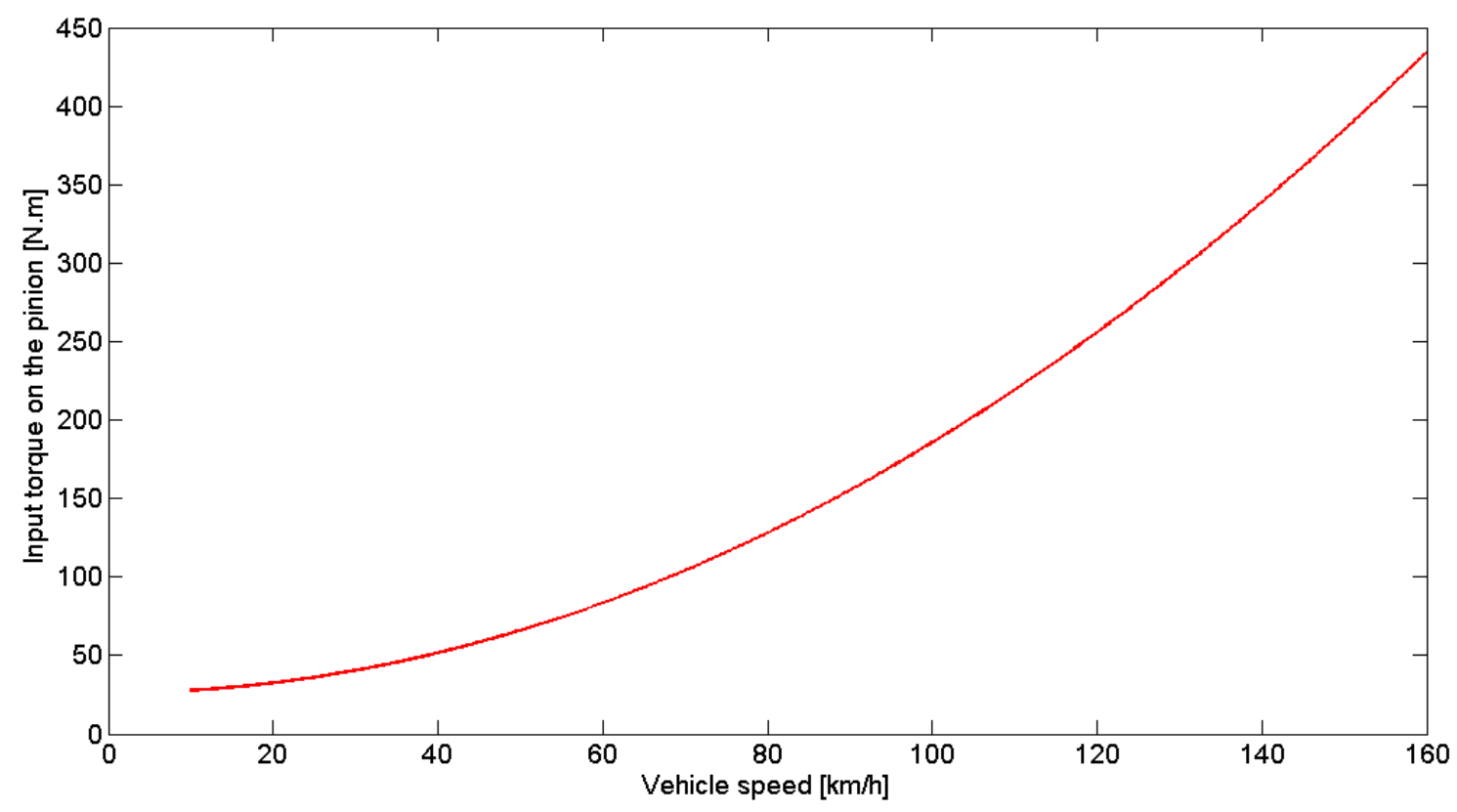

Figure A1. Input pinion torque for the considered case study 